\title{
Intestinal development and homeostasis require activation and apoptosis of diet-reactive T cells
}

\author{
Alexander Visekruna, ${ }^{1}$ Sabrina Hartmann, ${ }^{1}$ Yasmina Rodriguez Sillke, ${ }^{2}$ Rainer Glauben, ${ }^{2}$ Florence Fischer, ${ }^{1}$ Hartmann Raifer, ${ }^{3}$ \\ Hans Mollenkopf, ${ }^{4}$ Wilhelm Bertrams, ${ }^{5}$ Bernd Schmeck,, ${ }^{5}$ Matthias Klein, ${ }^{6}$ Axel Pagenstecher, ${ }^{7}$ Michael Lohoff, ${ }^{1}$ Ralf Jacob, ${ }^{8}$ \\ Oliver Pabst, ${ }^{9}$ Paul William Bland, ${ }^{10}$ Maik Luu, ${ }^{1}$ Rossana Romero, ${ }^{1}$ Britta Siegmund, ${ }^{2}$ Krishnaraj Rajalingam, ${ }^{11}$ and Ulrich Steinhoff ${ }^{1}$ \\ IInstitute for Medical Microbiology and Hospital Hygiene, Philipps University of Marburg, Germany. ${ }^{2}$ Medical Department for Gastroenterology, Infectious Diseases and Rheumatology, Campus Benjamin \\ Franklin, Charité - Universitätsmedizin Berlin, Germany. ${ }^{3}$ Flow Cytometry Core Facility, Philipps University Marburg, Germany. ${ }^{4}$ Max Planck Institute for Infection Biology, Core Facility Microarray/Genomics, \\ Berlin, Germany. ${ }^{5}$ Institute for Lung Research, Universities of Ciessen and Marburg Lung Center (UGMLC), Member of the German Center for Lung Research (DZL), Philipps University Marburg, Germany. \\ ${ }^{6}$ Institute for Immunology, University Medical Center, Mainz, Germany. ${ }^{7}$ Department of Neuropathology, Philipps University of Marburg, Germany. ${ }^{8}$ Department of Cell Biology and Cell Pathology, Philipps \\ University of Marburg, Germany. ${ }^{9}$ Institute of Molecular Medicine, Rheinisch-Westfälische Technische Hochschule Aachen University, Aachen, Germany. ${ }^{10}$ Department of Microbiology \& Immunology, \\ Gothenburg University, Gothenburg, Sweden. "Cell Biology Unit, University Medical Center, Mainz, Germany.
}

\begin{abstract}
The impact of food antigens on intestinal homeostasis and immune function is poorly understood. Here, we explored the impact of dietary antigens on the phenotype and fate of intestinal T cells. Physiological uptake of dietary proteins generated a highly activated $\mathrm{CD} 44^{+} \mathrm{Helios}^{+} \mathrm{CD} 4^{+} \mathrm{T}$ cell population predominantly in Peyer patches. These cells are distinct from regulatory $T$ cells and develop independently of the microbiota. Alimentation with a protein-free, elemental diet led to an atrophic small intestine with low numbers of activated T cells, including Tfh cells and decreased amounts of intestinal IgA and IL-10. Food-activated CD44+Helios+CD4+ $\mathrm{T}$ cells in the Peyer patches are controlled by the immune checkpoint molecule PD-1. Blocking the PD-1 pathway rescued these T cells from apoptosis and triggered proinflammatory cytokine production, which in IL-10-deficient mice was associated with intestinal inflammation. In support of these findings, our study of patients with Crohn's disease revealed significantly reduced frequencies of apoptotic CD4 ${ }^{+} \mathrm{T}$ cells in Peyer patches as compared with healthy controls. These results suggest that apoptosis of diet-activated T cells is a hallmark of the healthy intestine.
\end{abstract}

\section{Introduction}

Immunological tolerance to environmental factors such as intestinal bacteria and food antigens is an active, multilayered process, and its breakdown leads to hyperactivation of mucosal $\mathrm{T}$ and B cells and subsequent development of intestinal pathologies (1-3). Successful dietary intervention therapies in patients suffering from celiac disease, food allergies, and inflammatory bowel disease (IBD) demonstrate that diet contains immunologically relevant antigens (4-6). Yet, our understanding of diet-specific immune reactivity is largely derived from $\mathrm{T}$ cell receptor (TCR) transgenic mice and model antigens where tolerance mechanisms comprising clonal anergy, deletion, and induction of regulatory $\mathrm{T}$ cells (Tregs) have been shown (7-9). These data reveal that the contribution of clonal anergy/deletion versus active suppression by Tregs depends on type, dose, and frequency of applied antigens. Even though the vast majority of peripheral Tregs (pTregs) in the lamina propria (LP) of the small intestine is induced by normal food, oral tolerance is still intact if functional Treg levels are strongly reduced $(10,11)$.

Authorship note: AV and SH contributed equally to this work. Conflict of interest: The authors have declared that no conflict of interest exists. Copyright: (c) 2019, American Society for Clinical Investigation. Submitted: December 4, 2017; Accepted: February 19, 2019; Published: April 2, 2019 Reference information: / Clin Invest. 2019;129(5):1972-1983. https://doi.org/10.1172/JCI98929.
Although the LP is not considered a typical site of immune induction, Peyer patches (PPs) are specialized lymphoid follicles known for effective stimulation of B and T cells by luminal antigens. Surprisingly, little attention has been paid to their role in tolerance against dietary antigens. This might be due to controversial findings showing, on the one hand, that tolerance occurs in PP-deficient mice and, on the other hand, that PPs are required for oral tolerance (12-15).

Here, we investigated the occurrence of diet-activated $\mathrm{T}$ cells in various tissues and characterized their phenotype and fate. We observed that recognition of dietary antigens is essential for the cellular and functional maturation of the small intestine, including generation of Tfh cells and IgA production. In the healthy murine and human gut, food-activated $\mathrm{CD} 4^{+} \mathrm{T}$ cells in PPs exhibited a proapoptotic phenotype characterized by the transcription factor Helios and the programmed cell death protein 1 (PD-1). In contrast, low Helios expression and reduced apoptosis were observed in $\mathrm{PP} \mathrm{CD} 4^{+} \mathrm{T}$ cells of patients with IBD, suggesting that activation and subsequent death of food-reactive $\mathrm{T}$ cells is a hallmark of intestinal homeostasis.

\section{Results}

PPs harbor a population of activated Helios ${ }^{+}$Foxp $3^{-} C D 4^{+} T$ lymphocytes. First, we addressed the question of whether normal dietary antigens leave a signature of immune activation in nontransgenic animals. To differentiate between stimulation by microbial and 
A

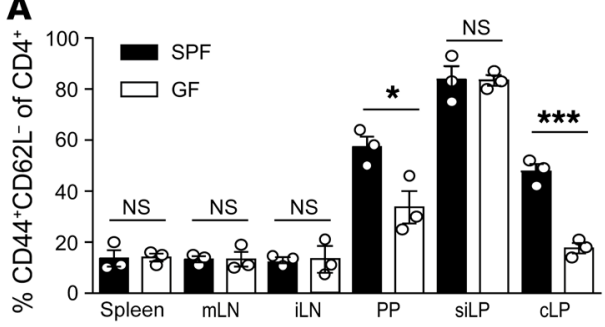

B

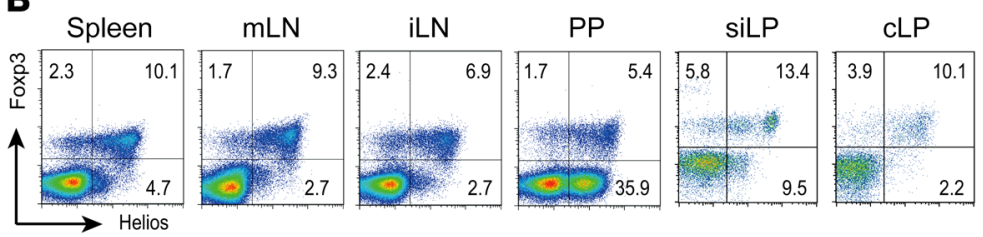

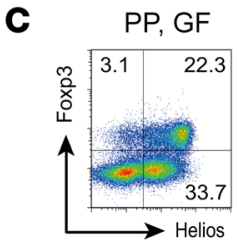

$\mathbf{F}$

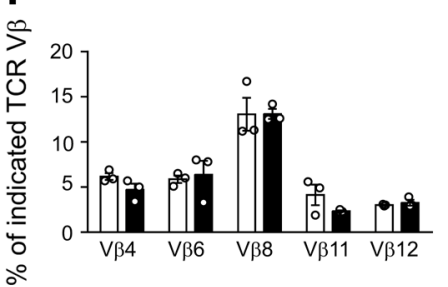

D

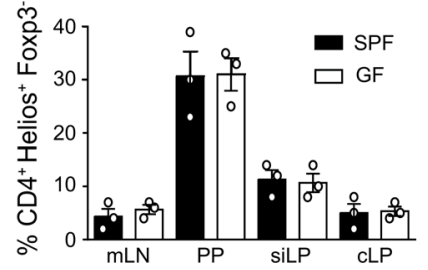

G

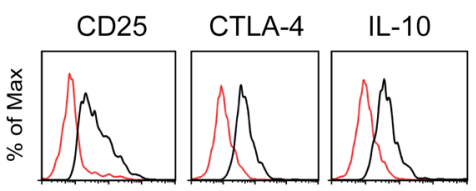

E

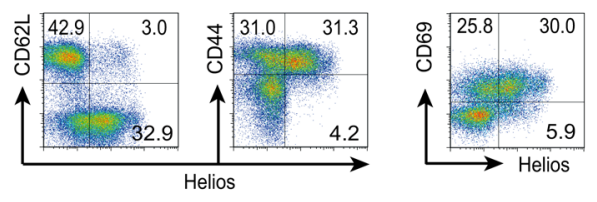

H

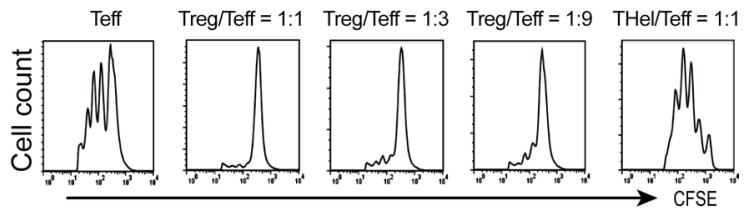

Figure 1. Helios ${ }^{+}$Foxp3-CD4+ $T$ cells accumulate in Peyer patches. (A) Percentage of $C D 44^{+} C D 62 L^{-} C D 4^{+} T$ cells in spleen, mLNs, inguinal lymph nodes (iLNs), PPs, siLP, and cLP of SPF and GF mice ( $n=6,1$ of 2 experiments is shown). (B) Representative dot plots of CD4 ${ }^{+}$T cells from SPF mice expressing Helios and Foxp3 in indicated organs $(n=6)$. (C) Expression of Helios and Foxp3 on gated CD4+ T cells of PPs from GF mice $(n=5)$. (D) Distribution of Helios ${ }^{+}$Foxp3 $^{-} \mathrm{CD}^{+} \mathrm{T}$ cells in indicated tissues of SPF and GF mice $(n=6,1$ of 2 experiments is shown). (E) Expression of Helios, CD62L, CD44, and CD69 in PP CD4+ T cells from SPF mice $(n=6)$. (F) TCR V $\beta$ repertoire of Helios ${ }^{+}$Foxp3-CD4+ T cells (white) and Tregs (black) derived from PPs of SPF mice $(n=5,1$ of 2 experiments is shown). (C) Analysis of CD25, CTLA-4, and IL-10 in Helios ${ }^{+}$Foxp3-CD4+ $4^{-}$cells (red) and Tregs (black) from PPs of SPF mice ( $n=3$ ). (H) In vitro suppression assay of $\mathrm{CD} 4^{+} \mathrm{T}$ responder cells (Teff) in the presence of in vitro-generated Tregs or $\mathrm{CD} 44^{+} \mathrm{CD}^{+} \mathrm{L}^{-} \mathrm{Helios}^{+} \mathrm{Foxp} 3^{-} \mathrm{CD} 4^{+} \mathrm{T}$ cells (THel) enriched from PPs of DEREG mice. Data are representative of $2(\mathbf{A}-\mathbf{D}$ and $\mathbf{F})$ or $3(\mathbf{E}, \mathbf{G}$, and $\mathbf{H})$ independent experiments. Error bars indicate mean \pm SD. Data were analyzed using the Student's $t$ test; ${ }^{*} P<0.05,{ }^{* * *} P<0.001$.

dietary antigens, intestinal and nonintestinal tissues of specific pathogen-free (SPF) and germ-free (GF) mice were screened for activated $\mathrm{T}$ cells. In contrast to spleen and mesenteric lymph nodes (mLNs), the majority of $\mathrm{CD} 4^{+} \mathrm{T}$ cells in PPs and small intestinal lamina propria (siLP) exhibited an antigen-experienced phenotype with high expression of CD44. In line with previous reports, GF mice revealed lower frequencies of activated $\mathrm{CD} 44^{+}$ CD62 $\mathrm{L}^{-} \mathrm{T}$ cells in PPs and colonic LP (cLP), indicating that this population includes both microbiota-dependent and -independent $\mathrm{T}$ cells (Figure 1A) (16).

Activated $\mathrm{T}$ lymphocytes, including Foxp $3^{+}$and Foxp3- $\mathrm{T}$ cell subsets, were shown to express the transcription factor Helios (17). Markedly increased frequencies (25\%-35\%) of Helios ${ }^{+} \mathrm{Foxp}^{-} \mathrm{CD}^{+}$ $\mathrm{T}$ cells were found in PPs compared with low frequencies $(<10 \%)$ in other organs (Figure 1B). Microbiota-independent Helios ${ }^{+}$ CD4 T cells, as shown in GF or antibiotic-treated (ATB-treated) SPF mice, were mainly found in PPs and to a lesser extent in the siLP (Figure 1, C and D, and Supplemental Figure 1; supplemental material available online with this article; https://doi.org/10.1172/ JCI98929DS1) and exhibited an antigen-experienced phenotype with high expression of CD44, CD69, and a low level of CD45RB and CD62L (Figure 1E and Supplemental Figure 2). As the role of Helios is controversial, we tested PP-derived Helios ${ }^{+} \mathrm{Foxp} 3^{-} \mathrm{CD} 4^{+}$
$\mathrm{T}$ cells for their regulatory function $(18,19)$. Although the usage of TCR V $\beta$ chains was broad and similar to Tregs, these cells lacked expression of CD25, CTLA-4, and IL-10, all typically expressed by Tregs (Figure 1, F and $\mathrm{G}$ ).

Moreover, Helios ${ }^{+} \mathrm{Foxp}^{-} \mathrm{CD}^{+}{ }^{+} \mathrm{PP} \mathrm{T}$ cells were not able to suppress proliferation of effector $\mathrm{T}$ cells (Figure $1 \mathrm{H}$ ), did not secrete IL-4, IFN- $\gamma$, or IL-17 after polyclonal stimulation, and were distinct from a subgroup of latency-associated peptide-expressing (LAP-expressing) Tregs, shown to produce IL-10 and TGF- $\beta$ (Supplemental Figure 3) (20).

Helios ${ }^{+}$Foxp $3^{-} \mathrm{CD}^{+} \mathrm{T}$ cells in PPs are activated by dietary antigens. As food is the major source of antigens in GF mice, and thus might explain the high frequency of Helios ${ }^{+} \mathrm{Foxp}^{-} \mathrm{CD}^{+} \mathrm{T}$ cells, we assumed that this population should be affected if animals were kept on an antigen-free, elemental diet (ED). Low proliferation of PP CD4 $4^{+} \mathrm{T}$ cells in ED mice resulted in a vastly decreased frequency and number of Helios ${ }^{+} \mathrm{Foxp}^{-} \mathrm{CD}^{+} \mathrm{T}$ cells as compared with animals kept on conventional diet (ConvD). Much less pronounced, but still affected by ED, was the number of Tregs in PPs despite unaltered frequencies (Figure 2, A-D).

With exception of the suckling period, the occurrence of Helios ${ }^{+} \mathrm{Foxp}^{-} \mathrm{CD}^{+} \mathrm{T}$ cells in ConvD and their decline in ED mice was age independent (Supplemental Figure $4, \mathrm{~A}-\mathrm{C}$ ). 
A

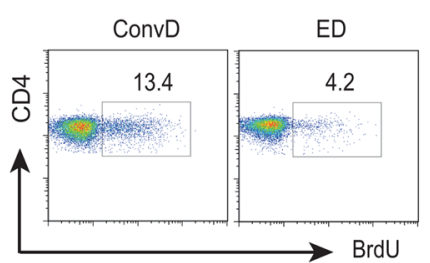

B

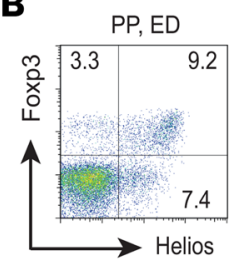

C

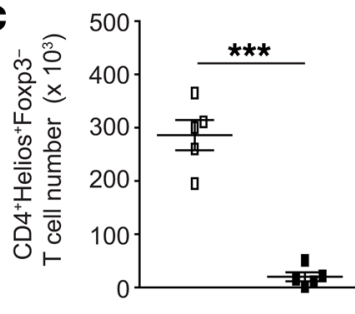

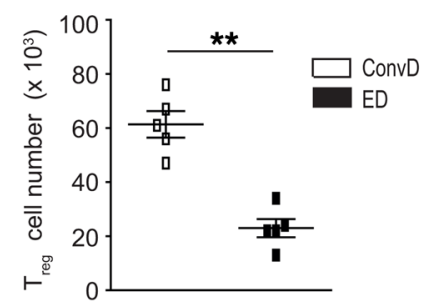

$\mathbf{F}$

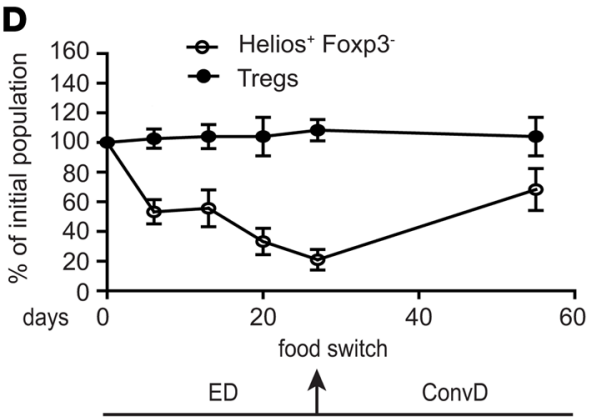

$\mathbf{E}$

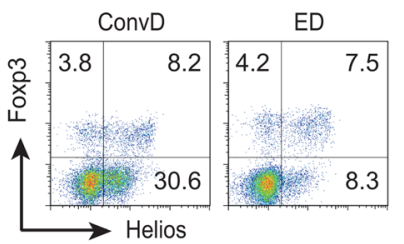

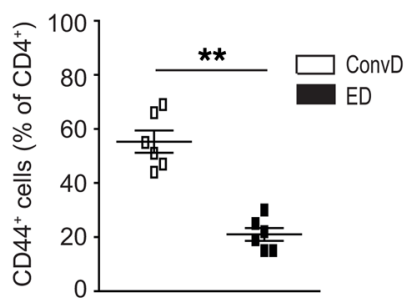

Figure 2. Helios ${ }^{+}$Foxp3-CD4 ${ }^{+}$T cells are food antigen-dependent. (A) Proliferation of PP CD4 ${ }^{+} T$ cells (BrdU ${ }^{+}$) of mice kept on ConvD or ED was determined by flow cytometry $(n=3)$. (B) Frequency of Helios ${ }^{+}$Foxp3 $^{-}$CD4 $4^{+}$T cells in PPs of ED mice. (C) Absolute cell numbers of Helios ${ }^{+}$Foxp3 $3^{-}$CD4 ${ }^{+}$T cells (left) and Tregs (right) in PPs of ConvD and ED mice $(n=5)$. (D) ConvD of SPF mice was switched to ED for 27 days and then back to ConvD. Frequencies of Tregs and Helios $^{+}$Foxp3-CD4 ${ }^{+}$T cells in PPs refer to ConvD mice, set at 100\% $(n=6)$. (E and F) SPF mice were fed ConvD or ED 27 days prior to analysis of Foxp3 and Helios (E) or total CD44+ $T$ cell numbers within the PP CD4+ T cell population (F) $(n=6)$. Data are representative of $2(\mathbf{D}-\mathbf{F})$ or $3(\mathbf{A}-\mathbf{C})$ independent experiments. Error bars indicate mean \pm SD. Data were analyzed using the Student's $t$ test; ${ }^{* *} P<0.001,{ }^{* * *} P<0.001$.

To study kinetics of food antigen-dependent expansion of Foxp3-Helios ${ }^{+}$and Foxp3 ${ }^{+} \mathrm{CD}^{+}{ }^{+} \mathrm{T}$ cells, ConvD was replaced by ED for 4 weeks and then switched to ConvD again. A gradual decline in the frequencies of Helios ${ }^{+} \mathrm{Foxp}^{-} \mathrm{CD}^{+} \mathrm{T}$ cells in PPs was observed with the duration of antigen-free alimentation. These levels returned to normal after ED was replaced by ConvD. In contrast, frequencies of Foxp $3^{+}$Tregs were not altered by a change of diet (Figure 2D). Flow cytometric analysis of PP CD4 $4^{+} \mathrm{T}$ cells indicated that the frequency of activated $\mathrm{CD} 44^{+} \mathrm{Helios}^{+} \mathrm{Foxp}^{-}$ $T$ cells was affected by ED (Figure 2, E and F). The effect of dietary antigens on total PP CD $4^{+} \mathrm{T}$ cells was also seen in GF animals. GF mice fed ED showed further declined frequencies and total numbers of Helios ${ }^{+} \mathrm{Foxp}^{-} \mathrm{CD} 4^{+} \mathrm{T}$ cells in the PPs, as compared with GF mice kept on ConvD. Of note, despite the unaltered frequency of the Foxp $3^{+}$population, the low intestinal cellularity in GF mice affected total numbers of Tregs, but not as much as the Helios ${ }^{+}$ non-Treg population (Supplemental Figure 5, A-C).

We conclude that the intestinal cellularity is influenced by both microbiota and nutrition, but the expansion of Helios ${ }^{+} \mathrm{Foxp} 3^{-} \mathrm{CD}^{+}$ $\mathrm{T}$ cells is only dependent on dietary proteins.

Dietary antigens mediate immunological maturation of the small intestine. We next investigated the long-term effects that lack of food antigens has on organ development. Macroscopic examination of animals fed ED showed a reduced diameter of the small intestinal tube with marginal PPs, whereas the spleen and colon were normal (Figure 3A). Immunohistological and FACS analysis of PPs revealed reduced numbers of $\mathrm{CD} 4^{+} \mathrm{T}$ cells in germinal centers (GCs) of ED mice, including PD- $1^{+} \mathrm{Helios}^{+} \mathrm{CXCR}^{+} \mathrm{T}$ th cells (Figure 3, B-E and Supplemental Figure 6, A-C). Approximately one-third of Helios ${ }^{+}$Foxp3 $^{-} \mathrm{T}$ cells expressed the Tfh marker CXCR5, whereas two-thirds remained CXCR5 negative (Supplemental Figure 6D).
Despite unaltered frequencies of $\mathrm{B}$ and $\mathrm{CD} 4^{+} \mathrm{T}$ cells, lack of dietary antigens resulted in reduced absolute numbers of $\mathrm{CD} 4^{+}$ $\mathrm{T}$ and $\mathrm{B}$ cells in PPs, mLNs, and siLP, but not in colon or spleen (Figure 3C and Supplemental Figure 7). In addition, PPs of ED animals contained considerably reduced numbers of activated B cells in the $\mathrm{GC}$ and diminished frequencies of $\operatorname{IgA}^{+} \mathrm{B}$ lymphocytes. This explains the low amounts of secretory IgA in the small intestines of ED mice (Figure 3, F and G, Supplemental Figure 8). Importantly, normal thymic $\mathrm{T}$ cell development, together with unaltered $\mathrm{T}$ and $\mathrm{B}$ cell numbers in the spleen, demonstrated that food antigen deficiency does not disturb systemic lymphocyte development (Supplemental Figure 9) but specifically affects expansion and survival of lymphocytes within the small intestine.

Helios induction by sustained TCR-restricted antigen stimulation. To investigate whether dietary antigens are recognized in a TCR-specific manner, we analyzed RAG-sufficient OT-II mice in which the vast majority of $\mathrm{T}$ cells expresses the OVA-specific $\mathrm{Va} 2^{+} \mathrm{TCR}$ and a minor population of $\mathrm{T}$ cells, including diet-reactive $\mathrm{T}$ cells, expresses an endogenous $\mathrm{V} \alpha 2^{-}$, polyclonal TCR that preferentially accumulated in PPs (Figure 4A). In the absence of OVA, most V $\alpha 2^{+}{ }^{+}$cells were Helios ${ }^{-}$, whereas more than $10 \%$ of the $\mathrm{V} \alpha 2^{-} \mathrm{CD} 4^{+} \mathrm{T}$ cells revealed a signature of food antigen activation in PPs but not in spleen or mLNs (Figure 4B). Correspondingly, OVA-supplemented drinking water triggered the expansion of Helios ${ }^{+} \mathrm{Foxp}^{-} \mathrm{V} \alpha 2^{+} \mathrm{T}$ cells in PPs (Figure 4C), but also in mLNs and spleen (data not shown). OVA-stimulated $\mathrm{V} \alpha 2^{+} \mathrm{PP}$ $\mathrm{T}$ cells differentiated into Helios ${ }^{+}$Foxp $3^{-}$or Helios ${ }^{+} \mathrm{Foxp}^{+}$phenotypes, demonstrating that the majority of $\mathrm{Va}^{+} \mathrm{T}$ cells expressed Helios independently of Foxp3 and only a small fraction differentiated into Helios ${ }^{+}$Foxp $^{+}$Tregs (Figure 4D). In vitro studies further confirmed that Foxp3-independent induction of Helios expression requires recognition of cognate antigen (Supplemental Figure 10). 
A

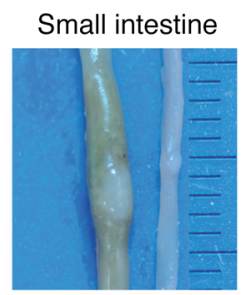

ConvD ED
Colon

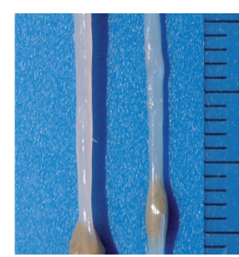

ConvD ED
Spleen

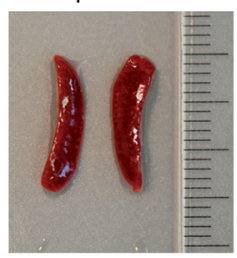

ConvD ED
B
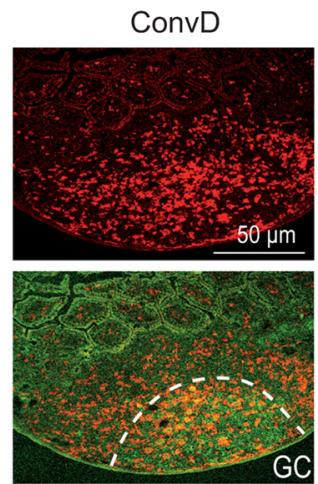

$\mathrm{mLN}$
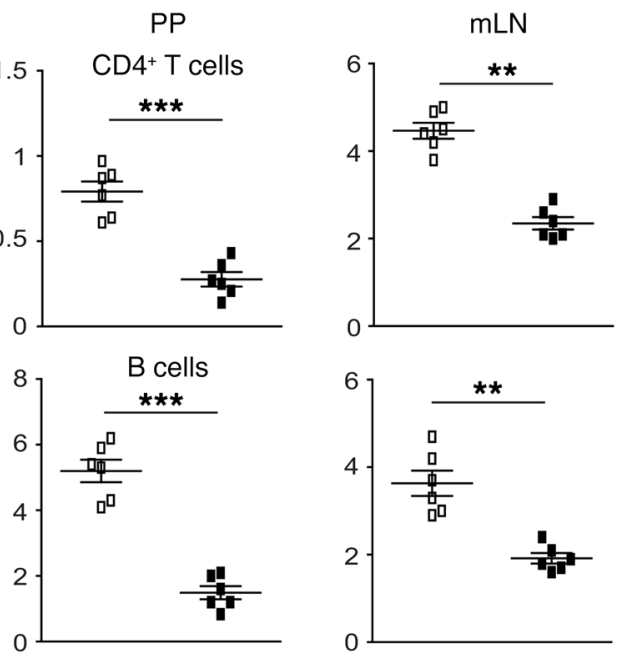

PP
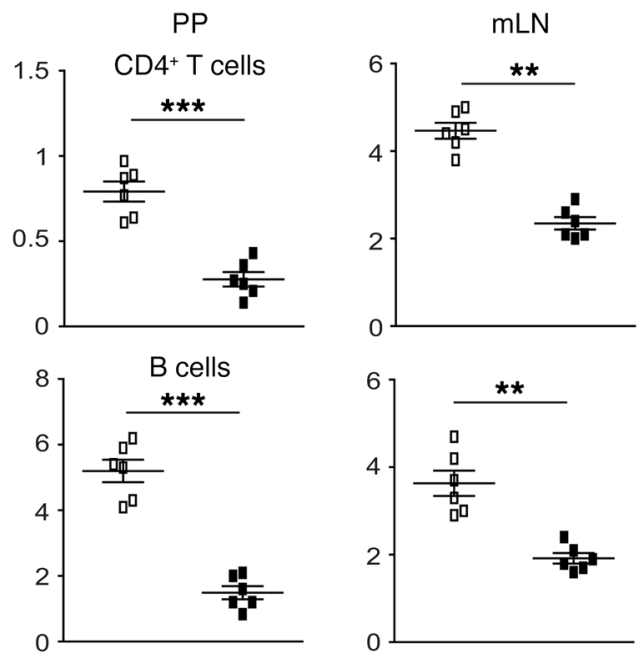

ED

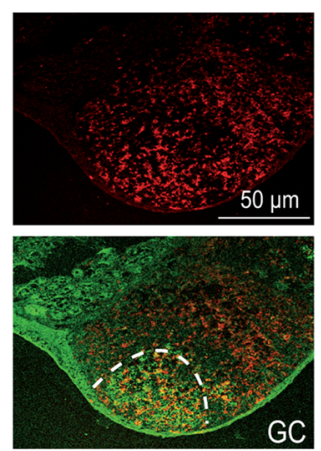

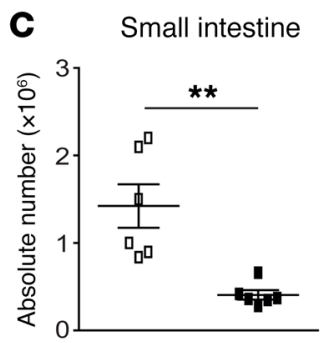
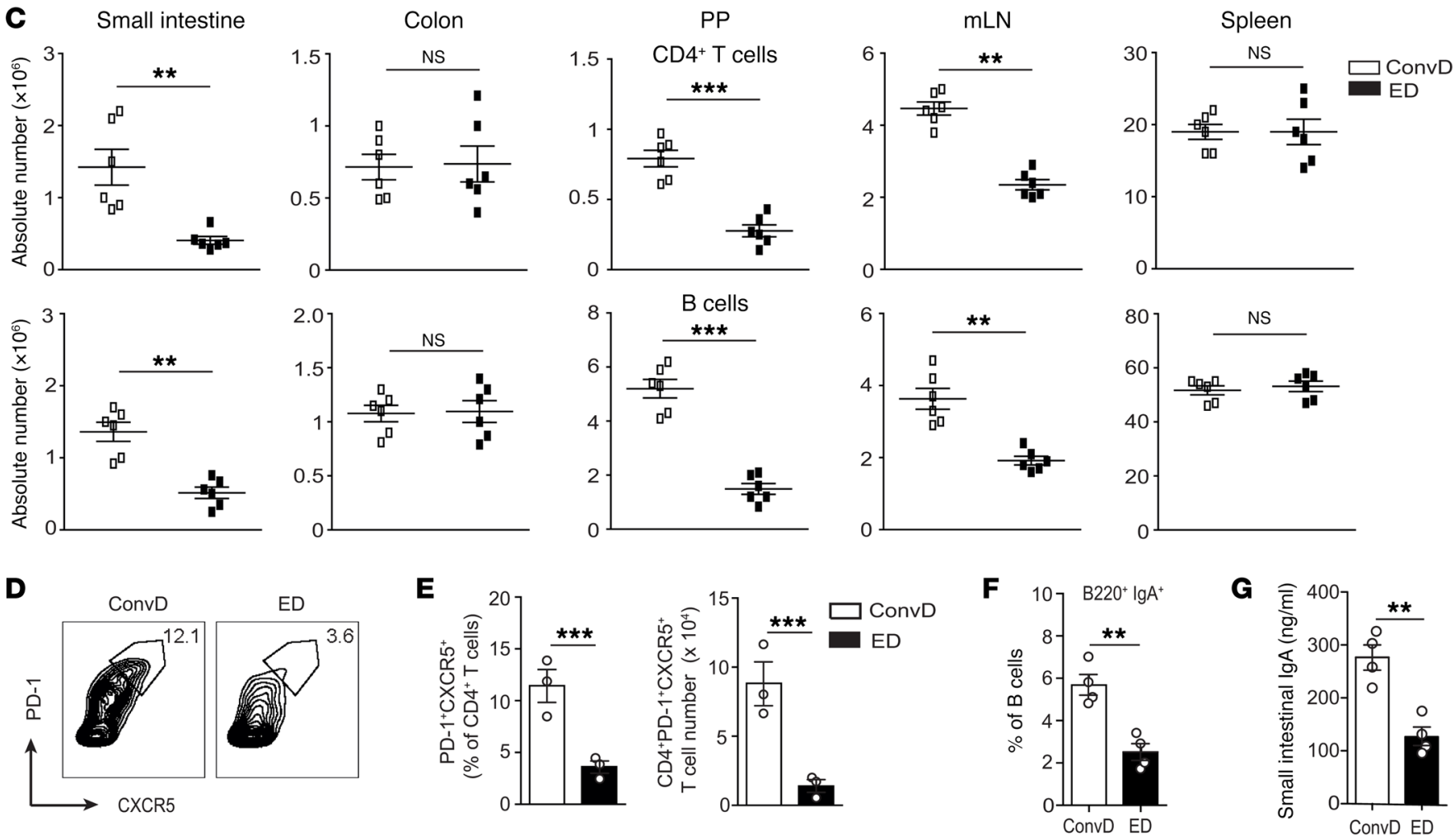

Figure 3. Food antigens are required for immunological maturation of the small intestine. (A) Macroscopic appearance of organs from animals kept on ConvD or ED for 4 generations. (B) Immunohistology of PPs from ConvD and ED mice stained for CD4 (red) and the germinal center marker GL7 (green) ( $n=$ 4). Germinal centers are outlined with dashed line. (C) Total numbers of $C D 4^{+} T$ and $B$ cells in indicated organs of ConvD and ED mice $(n=6)$. (D) FACS analysis showing percentages of CXCR5 hiPD- $1^{\text {hi }}$ Tfh cells within the PP CD4+ $T$ cells of ConvD and ED mice. (E) Frequencies and total cell number of CXCR5 hipD- $1^{\text {hi }}$ Tfh cells in PPs of ConvD and ED mice ( $n=6,1$ of 2 experiments is shown). (F) Frequencies of B220+ IgA+ cells in PPs of ConvD and ED mice ( $n=4)$. (C) Small intestinal IgA concentrations of ConvD and ED mice were measured by ELISA $(n=4)$. Data are representative of $2(\mathbf{A}-\mathbf{C})$ independent experiments. Error bars indicate mean $\pm \mathrm{SD}$. Data were analyzed using the Student's $t$ test; ${ }^{*} P<0.05,{ }^{* *} P<0.01,{ }^{* * *} P<0.001$.

These results show that induction of the Helios ${ }^{+}$Foxp3 ${ }^{-}$phenotype requires TCR-mediated recognition of dietary antigens, with $\mathrm{V} \alpha 2^{+} \mathrm{T}$ cells being specifically activated by OVA but not by other dietary antigens, whereas $\mathrm{V} \alpha 2^{-} \mathrm{T}$ cells react in the opposite way.

Dietary antigen impact on the transcriptional profile of $P P C D 4^{+}$ $T$ cells. Since stimulation with food antigens is crucial for the maturation of the intestinal immune system, we investigated the mRNA profile of $\mathrm{PP} \mathrm{CD} 4^{+} \mathrm{T}$ cells in response to dietary antigens and their activation state. We wondered whether continuous exposure to dietary antigens leads to a phenotype of exhaustion similar to that described for chronic viral infections. In contrast to $\mathrm{CD} 4^{+} \mathrm{T}$ cells from chronic viral infection, the transcriptional signature of ConvD-activated $\mathrm{CD} 4^{+} \mathrm{T}$ cells was slightly skewed toward exhaustion. $\mathrm{CD}^{+} \mathrm{T}$ cells from ConvD mice expressed increased mRNA for Lag3, Icos, Pdcd1, and Tigit as compared with ED mice (Figure 5A).

In accordance with our phenotypic analyses, the expression pattern of ConvD animals was markedly biased toward a Tfh cell signature, including transcripts for IL-21, Cxcr5, Bcl6, Pdcd1, and Ascl2. While Tfh cell differentiation may be controlled by a Bcl6or Ascl2 gene-centered network, the latter network seems to apply to Tfh cell polarization by dietary antigens, as illustrated by positive gene association upon ConvD treatment (Figure 5B). 
A

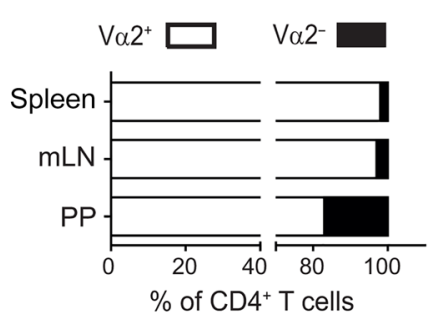

C

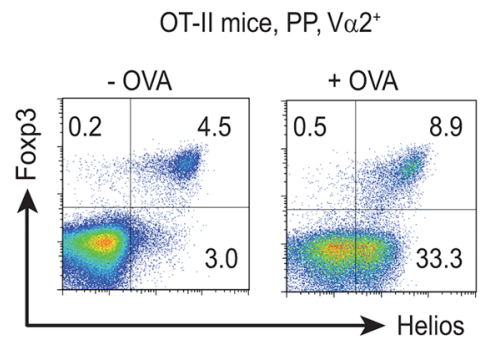

B

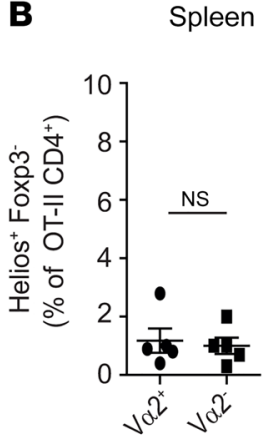

$\mathrm{mLN}$
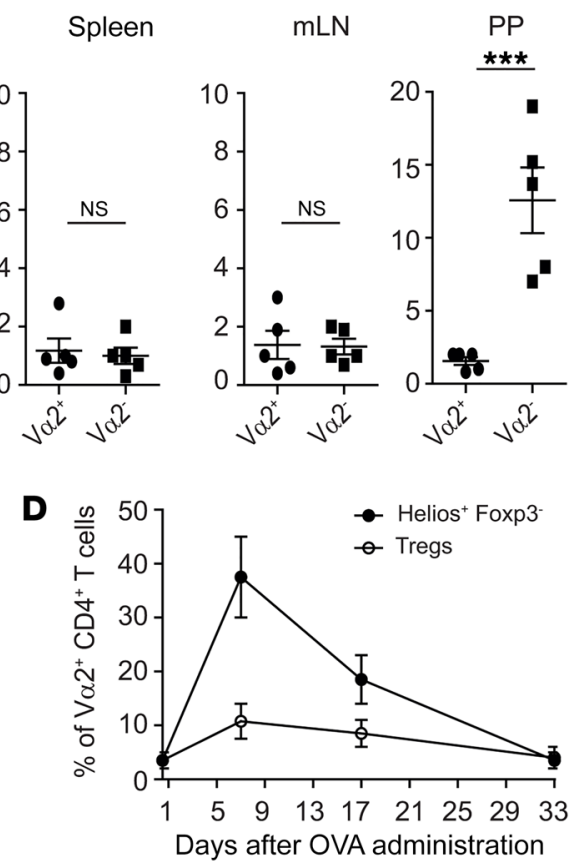

Figure 4. Induction of Helios is TCR-specific. (A) Frequencies of Ova-specific TCR tg $\mathrm{V} \alpha 2^{+}$ (white bars) and endogenous $\mathrm{V} \alpha 2^{-}$(black bars) $C D 4^{+} T$ cells in indicated organs of naive OT-II RAG ${ }^{+/+}$mice. (B) Frequencies of Helios ${ }^{+}$ Foxp3-CD4 ${ }^{+} \mathrm{T}$ cells within the $\mathrm{V} \alpha 2^{+}$and $\mathrm{V} \alpha 2^{-}$ populations in indicated organs of naive OT-II $\mathrm{RAC}^{+/+}$mice $(n=5)$. (C) Expression of Helios and Foxp3 in $\mathrm{V} \alpha 2^{+} \mathrm{PP} T$ cells without or after stimulation of OVA ( $1 \mathrm{mg} / \mathrm{ml})$ for 5 days. (D) Kinetics of Helios and Foxp3 expression in $\mathrm{V} \alpha 2^{+} \mathrm{CD} 4 \mathrm{PP} \mathrm{T}$ cells of OT-II mice given $1 \mathrm{mg} /$ $\mathrm{ml}$ OVA in drinking water for 5 days. Expression was analyzed by FACS at days 2,10 , and 23 after withdrawal of OVA $(n=4)$. Data are representative of 2 ( $C$ and $\mathbf{D}$ ) or 3 ( $\mathbf{A}$ and $\mathbf{B}$ ) independent experiments. Error bars indicate mean \pm SD. Data were analyzed using the Student's $t$ test; ${ }^{* * *} P<0.001$.
Finally, we compared the transcriptional profile of activated $\left(\mathrm{CD} 44^{+} \mathrm{CD} 62 \mathrm{~L}^{-}\right.$-Foxp3 $\left.3^{-}\right)$versus naive $\left(\mathrm{CD}_{4} 4^{-} \mathrm{CD} 6 \mathrm{~L}^{+}{ }^{+} \mathrm{Foxp}^{-}\right) \mathrm{CD}^{+}$ $\mathrm{T}$ cells in the PPs of ConvD mice. Gene enrichment analysis revealed a marked upregulation of genes that are associated with apoptosis and oxidative phosphorylation in activated $\mathrm{CD} 4^{+} \mathrm{T}$ cells as compared with their naive controls (Figure 5, C and D). In summary, these gene signatures show that not only the microbiota but also food antigens induce Tfh cells and further suggest that PP $\mathrm{CD} 4^{+} \mathrm{T}$ cells activated by dietary antigens are more prone to apoptosis than to exhaustion.

Food-reactive PP T cells undergo apoptosis and trigger IL-10 production. To further examine the fate of food antigen-reactive Helios $^{+} \mathrm{Foxp}^{-} \mathrm{CD}^{+} \mathrm{T}$ cells, we first analyzed the expression of molecules required for cell survival. While the majority of $\mathrm{CD} 4^{+}$ $\mathrm{T}$ cells in spleen and mLNs expressed the IL-7R $\alpha$ (CD127), a substantial population of $\mathrm{PP} T$ cells, including most food protein-reactive $T$ cells, downregulated this survival receptor (Figure 6, A and B). In addition, OX40 and Bcl-2, both essential for long-term survival of $\mathrm{CD} 4^{+} \mathrm{T}$ cells, were almost absent in food-reactive $\mathrm{T}$ cells but were strongly expressed in Tregs of PPs (Figure 6, C and D) (21). As lack of survival molecules is common in cells prone to apoptosis, we performed annexin V/PI staining for $\mathrm{T}$ and $\mathrm{B}$ cells of SPF and GF mice. Strong staining of annexin $V$ was exclusively seen within $\mathrm{CD}^{+} \mathrm{T}$ but not B cells in PPs of SPF and GF mice (Figure 6E and Supplemental Figure 11, A and B). The apoptotic signature was mainly confined to food-activated $\mathrm{CD} 44^{\text {hi }}$ Helios ${ }^{+}$Foxp $^{-} \mathrm{CD}^{+} \mathrm{T}$ cells (Figure 6, $\mathrm{F}$ and G) and was significantly decreased in animals fed ED (Figure 6H).

To define the pathway of apoptosis, sorted $\mathrm{CD} 44^{\mathrm{hi}} \mathrm{CD} 4^{+}$ and $\mathrm{CD} 44^{10} \mathrm{CD} 4^{+} \mathrm{T}$ cells from PPs of ConvD animals were analyzed for cleavage of poly (ADP-ribose) polymerase (PARP) and caspase activation. Strong cleavage of PARP together with activation of caspase- 3 and -8 but not caspase- 9 were seen in $\mathrm{CD} 44^{\text {hi }}$ but not in $\mathrm{CD} 44^{\text {lo }} \mathrm{T}$ cells (Figure 6I), suggesting that programmed cell death is the fate of diet-activated T cells in PPs of the healthy intestine.
Ingestion of apoptotic cells has been shown to induce IL-10 and to inhibit proinflammatory cytokine production, thus preventing chronic inflammation or autoimmunity $(22,23)$. Thus, we tested whether apoptotic cells are linked with the induction of IL-10 in PPs. In contrast to spleen and mLNs, substantial amounts of IL-10 were produced by cultured cells of PPs. Importantly, IL-10 secretion by PP-derived cells was dependent on dietary antigens, as only marginal amounts of IL-10 were detectable in ED animals (Supplemental Figure 12, A and B). Further, cocultures of macrophages with lymphocytes from various organs revealed that uptake of T lymphocytes from PPs but not spleen or mLNs triggered macrophage-derived IL-10 synthesis. Secretion of IL-10 correlated with the amount of dead cells, as staurosporine pretreatment further enhanced this effect (Supplemental Figure 12C).

Apoptosis of Helios ${ }^{+} \mathrm{Foxp}^{-} \mathrm{CD}^{+} \mathrm{T}$ cells is controlled by PD-1. PD-1 is known to be an important regulator of $\mathrm{T}$ cell activation and apoptosis (24). We thus tested the expression of PD-1 on both Helios $^{+}$and Helios- $\mathrm{T}$ cell populations in the PPs. Flow cytometric analysis revealed selective expression of PD- 1 in Helios ${ }^{+}$but not Helios ${ }^{-}$PP T cells (Figure 7, A and B). Further, PD-1 ligands PDL-1 and PDL-2 were found to be predominantly expressed on CD11 $\mathrm{b}^{+}$ and CD11 ${ }^{+}$APCs of the PPs (Figure 7C).

Next, we determined whether PD-1 signaling controls the response of PP CD4 ${ }^{+} \mathrm{T}$ cells. To this end, we either injected PD-1-blocking antibodies or isotype controls into normal C57BL/6 mice i.p. or added anti-PD-1 antibodies directly into PP cell cultures. Polyclonal stimulation of PP cell suspensions revealed that anti-PD-1 treatment but not isotype control rescues PP CD $4^{+} \mathrm{T}$ cells from apoptosis to become IFN- $\gamma$-secreting effector cells (Figure 7, D-F).

In inflammatory bowel disease, such as Crohn's disease (CD), a variety of models have been used, including the IL-10-KO mouse which develops inflammatory reactions closest to $\mathrm{CD}$ (25). We wondered whether modulation of the PD-1 pathway leads to disease 
A

60

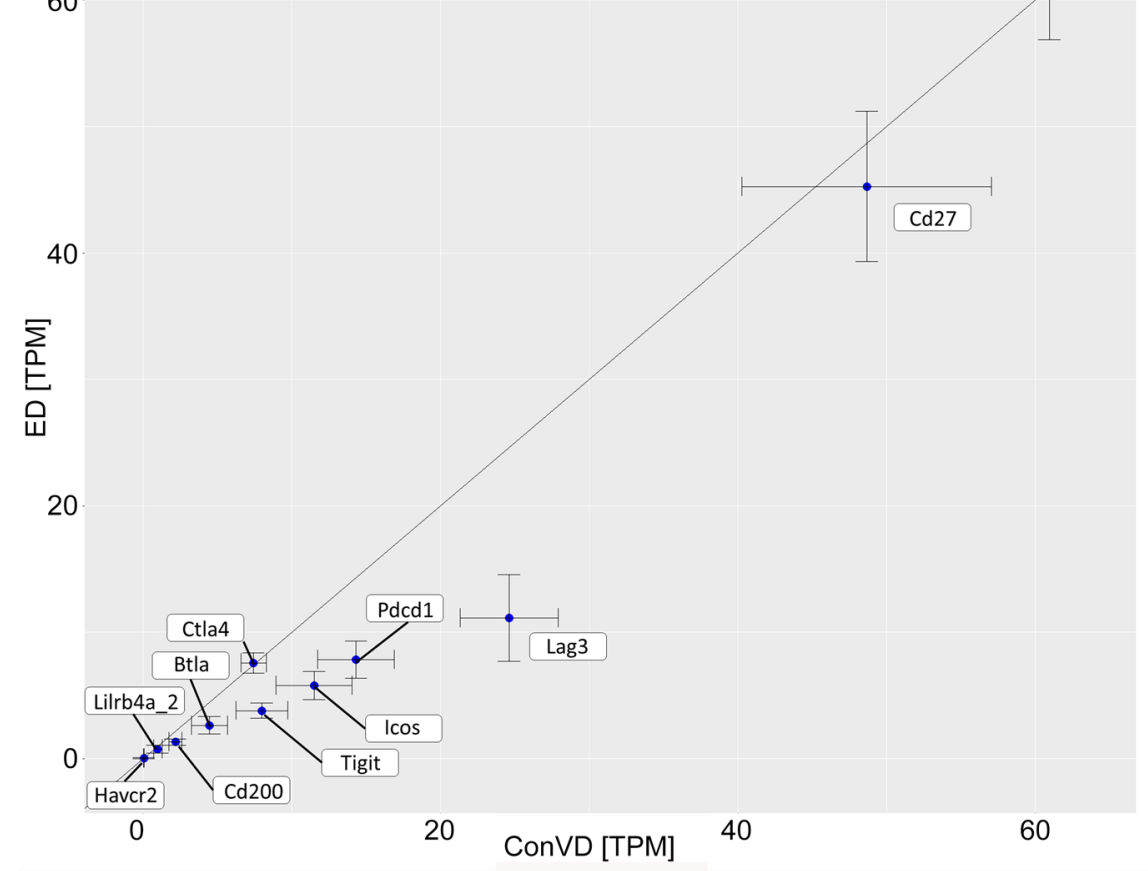

Figure 5. Transcriptional profiling of food antigendependent $\mathrm{CD}^{+} \mathrm{T}$ cells in PPs. (A) $\mathrm{CD} 4^{+} \mathrm{T}$ cells from PPs were sorted and analyzed by RNA sequencing. The gene expression signature of $\mathrm{T}$ cell exhaustion was compared between ConvD and ED mice. Each dot represents mean transcripts per million (TPM) \pm SD for 6 mice per group. (B) Key gene TPM associated with Tfh function were transformed to $Z$ scores and compared between ConvD and ED mice (6 mice per group). ASCL2 and Bcl6 target genes were investigated by Gene Set Enrichment Analysis (GSEA). (C and D) Genes identified by RNA sequencing of $\mathrm{CD} 44^{+} \mathrm{CD}^{-} \mathrm{LL}^{-}$Foxp3 $3^{-} \mathrm{CD} 4^{+}$and $\mathrm{CD} 44^{-}$ CD62L'Foxp3-CD4 ${ }^{+} T$ cells from PPs of ConvD mice were investigated by GSEA for enrichment of the oxidative phosphorylation pathway and apoptosis as defined in the KEGC database. NES, normalized enrichment score; FDR, false discovery rate.

B
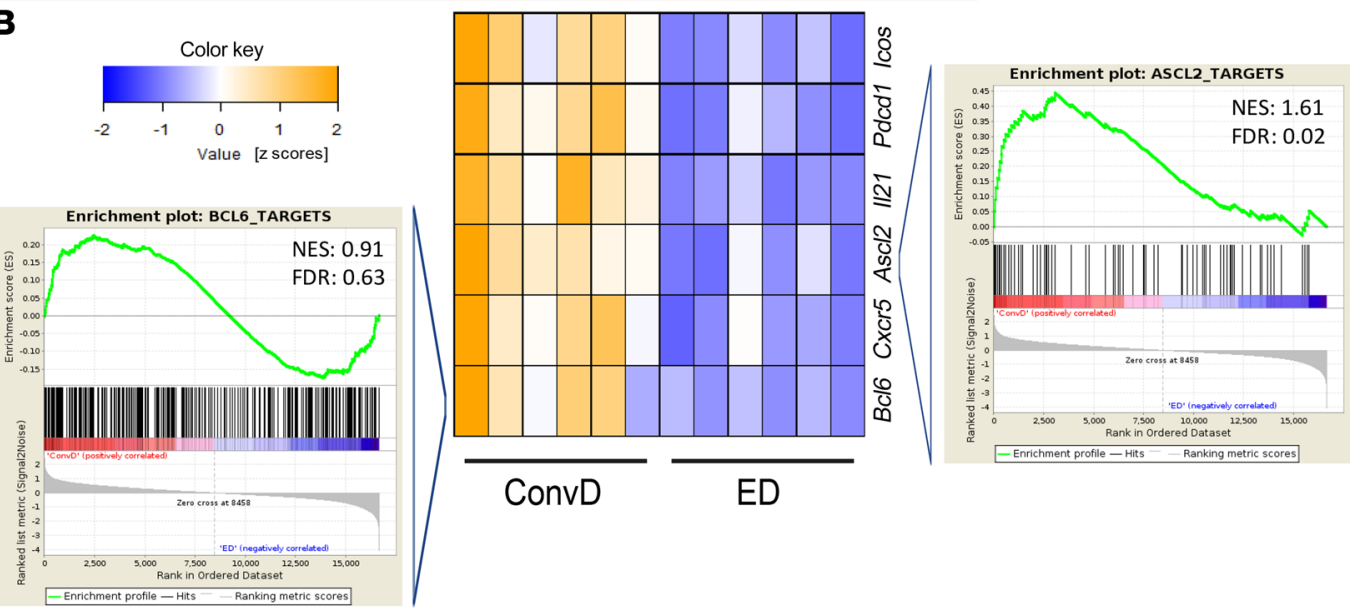

C

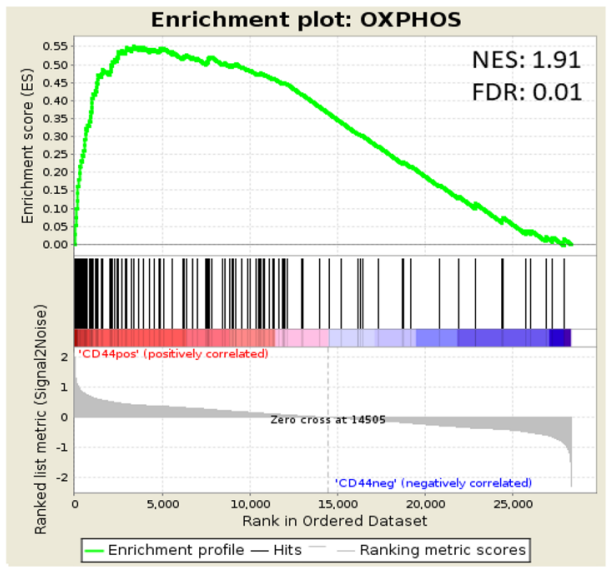

D

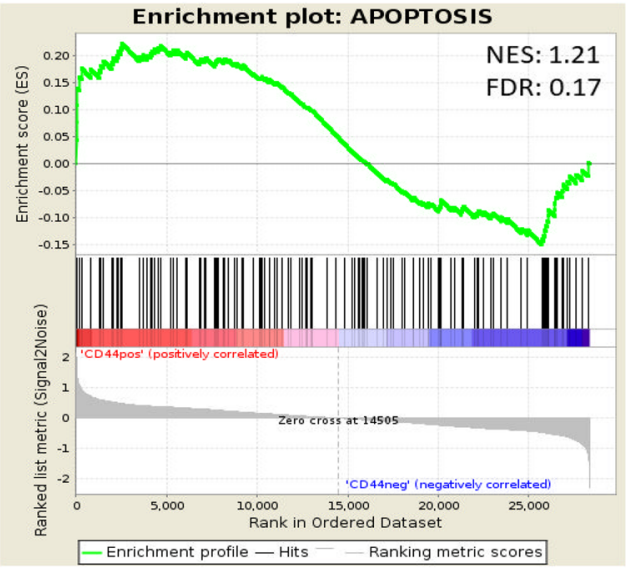


A

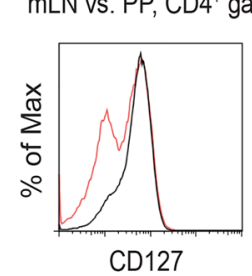

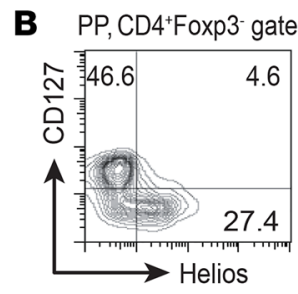

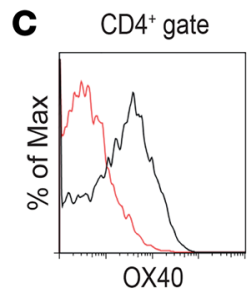

D

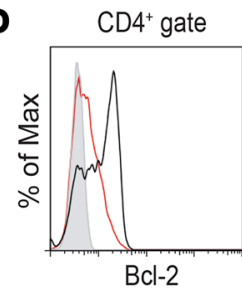

E
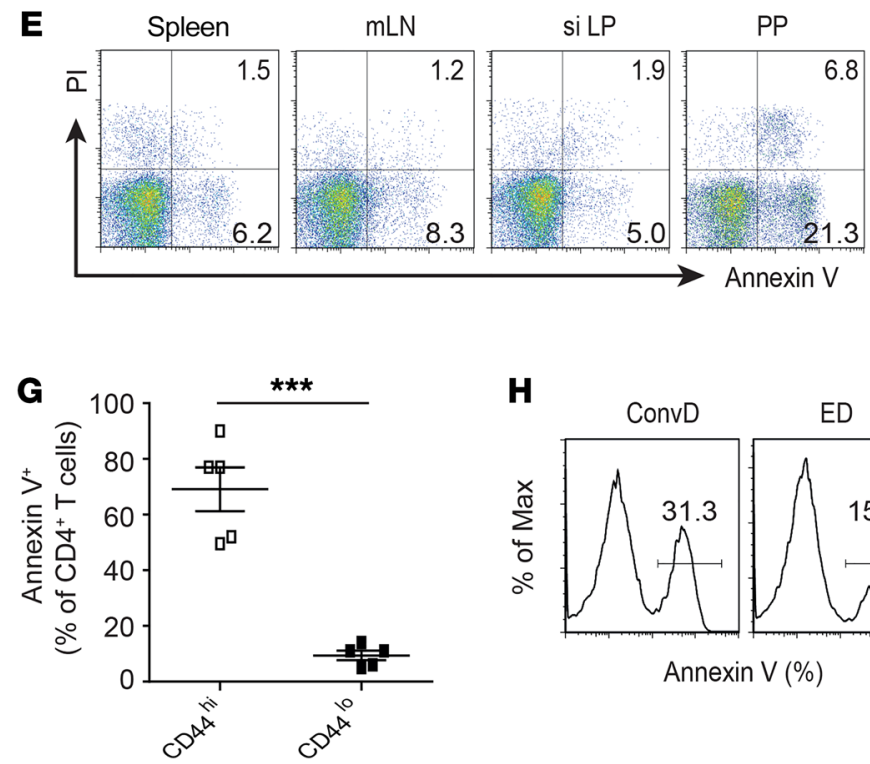

H

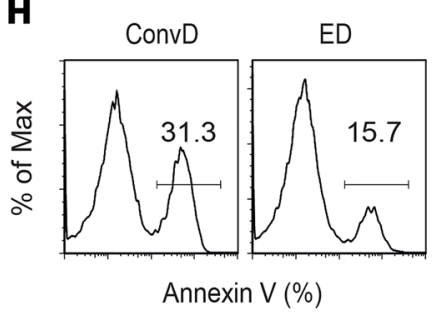

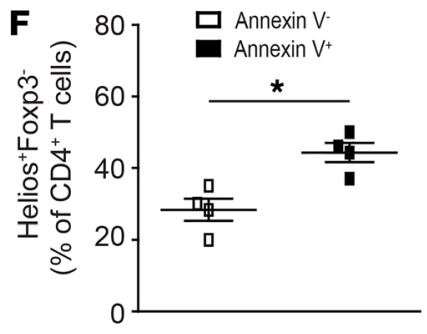

I

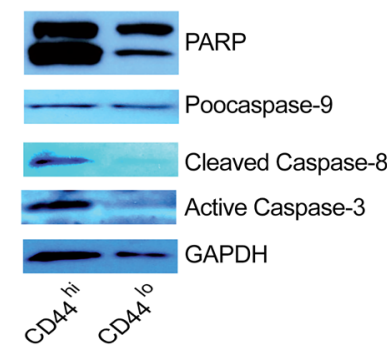

Figure 6. Food antigen-activated T cells undergo apoptosis in PPs. (A) Expression of CD127 on CD4+ $T$ cells derived from mLNs (black) and PPs (red) of ConvD mice. (B) Flow cytometric analysis of CD127 and Helios in viable Foxp3-CD4+ T cells from PPs of ConvD mice. (C and D) Expression OX40 and Bcl-2 in Helios ${ }^{+}$Foxp3 $^{-C D 4} 4^{+}$T cells (red) or Tregs (black) from PPs of Conv mice $(n=4)$. The filled area shows isotype control staining. (E) Frequencies of annexin V/ $\mathrm{Pl}^{+}$CD4 $4^{+} \mathrm{T}$ cells in spleen, mLNs, siLP, and PPs of ConvD mice. (F) Frequencies of Helios ${ }^{+}$Foxp3 $3^{-}$cells in annexin $\mathrm{V}^{+}$and annexin $\mathrm{V}^{-}$CD4 $4^{+} \mathrm{T}$ cells sorted from PPs of ConvD mice $(n=4)$. (G) Annexin V staining of CD4+CD44 hi and CD4+CD44 ${ }^{10} C D 4^{+} T$ cells from PPs of ConvD mice $(n=5)$. (H) Annexin $V^{+}$CD4 $4^{+} T$ cells derived from PPs of ConvD and ED mice $(n=5)$. (I) Immunoblot analysis of sorted CD44 hi and CD44 $4^{10} C D 4^{+} T$ cells from PPs of ConvD mice for cleavage of PARP and activation of caspases. Data are representative of 2 (F-I) or $3(\mathbf{A}-\mathbf{E})$ independent experiments. Results are expressed as mean \pm SD. Data were analyzed using the Student's $t$ test; ${ }^{*} P<0.05 ;{ }^{* *} P<0.001$.

progression in IL-10-deficient mice. In contrast to WT controls, IL-10-KO mice treated with anti-PD-1 mAb developed severe colitis, accompanied by enhanced cellularity of $\mathrm{T}$ cells and increased numbers of IFN $-\gamma^{+} \mathrm{CD} 4^{+} \mathrm{T}$ cells in the PPs (Supplemental Figure 13, A-D).

Although these data suggest that PD-1 immune checkpoint blockade in the absence of IL-10 favors colitis development, the precise contribution of $\mathrm{PP} \mathrm{Helios}^{+} \mathrm{CD} 4^{+} \mathrm{T}$ cells remains unclear.

Reduced apoptosis of PP T cells in patients with IBD. Finally, we investigated the apoptotic behavior of human PP CD4 $4^{+} \mathrm{T}$ cells in healthy controls and patients with CD. Biopsies from PPs of the terminal ileum were taken with written consent from persons who had undergone routine intestinal health surveillance or patients with clinically diagnosed $\mathrm{CD}$. The latter group was selected for discrete inflammation of the colon and/or ileum, whereas none of the controls showed signs of inflammation (Supplemental Table 1). To assure that $T$ cells were derived from PPs, lymphocytes were stained and gated for expression of the germinal center marker GL7 prior to further analysis. While approximately $40 \%$ of the $\mathrm{CD}^{+}{ }^{+} \mathrm{GL} 7{ }^{+} \mathrm{PP} \mathrm{T}$ cells from healthy controls were annexin $\mathrm{V}^{+}$, patients with $\mathrm{CD}$ revealed significantly lower frequencies of apop- totic PP T cells (approximately 22\%) (Figure 8, A and B). Increased survival of PP T cells in $\mathrm{CD}$ was reflected by enhanced expression of Bcl-2 in viable cells (Figure 8C). Consistent with the finding that Helios marks $\mathrm{CD}^{+} \mathrm{T}$ cells undergoing programmed cell death with subsequent downregulation of Bcl-2 $(26,27)$, the expression of Helios in Foxp3 ${ }^{-} \mathrm{CD} 4^{+} \mathrm{T}$ cells from PPs of patients with $\mathrm{CD}$ was significantly reduced as compared with healthy controls (Figure $8 \mathrm{D})$. These data suggest that high apoptosis of $\mathrm{PP} \mathrm{CD} 4^{+} \mathrm{T}$ cells is a homeostatic mechanism of the healthy gut.

\section{Discussion}

Although the value of nutritional treatment in patients with IBD was first reported over 30 years ago, a poor understanding of immunological mechanisms hinders both acceptance and use of medical diets $(28,29)$. From an immunological point of view, diet contains components of potential antigenicity that the immune system should not actively challenge. Accordingly, several studies have demonstrated that exposure to dietary antigens results in the generation of Tregs. However, the phenotype and fate of food-reactive $\mathrm{T}$ cells in the inductive tissue sites have received little attention. 
A

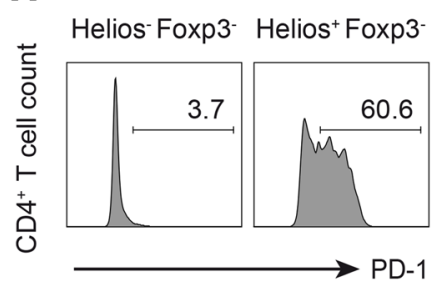

B

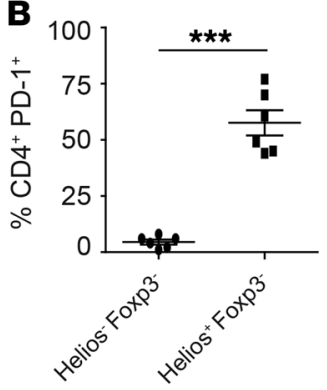

E

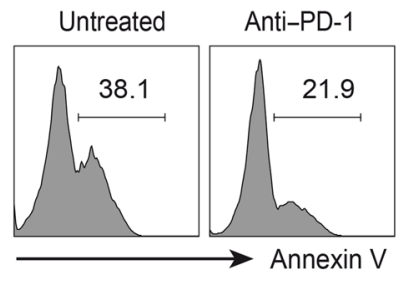

C

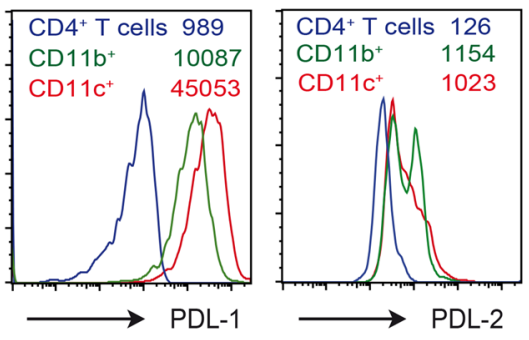

$\mathbf{F}$
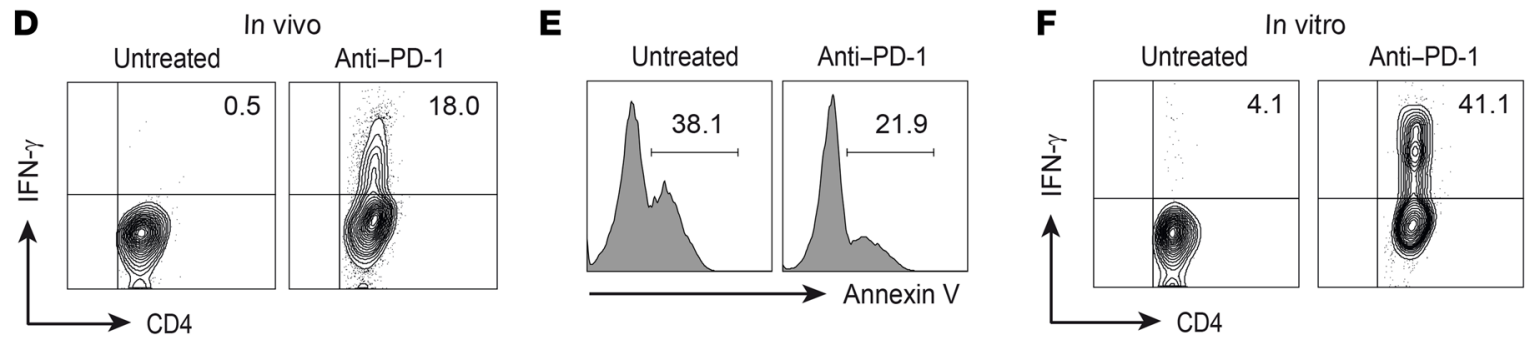

Figure 7. Anti-PD-1 treatment activates proinflammatory T cell responses in PPs. (A and B) Expression of PD-1 in Helios ${ }^{-}$Foxp3 $^{-}$and Helios ${ }^{+}$Foxp3 $3^{-} \mathrm{CD}^{+} \mathrm{PP}^{-}$ T lymphocytes $(n=6)$. (C) Expression of PD-L1 and PD-L2 in Cd11 b+ (green) and Cd11 ${ }^{+}$(red) APCs as well as in CD4+ T cells (blue) was analyzed by FACS. One representative of 3 similar experiments is shown. Numbers indicate the geometric mean fluorescence intensity (MFI) of PD-L1 and PD-L2. (D and E) Impact of in vivo anti-PD-1 treatment on IFN- $\gamma^{+}$and annexin $\mathrm{V}^{+}$CD4 ${ }^{+} \mathrm{T}$ cells in PPs of ConvD mice. (F) Effects of in vitro anti-PD-1 treatment on IFN- $\gamma$ expression in PP CD4 ${ }^{+} T$ cells. PP cell cultures were treated as described in Methods and the frequency of IFN- $\gamma^{+} \mathrm{CD} 4^{+} \mathrm{T}$ cells was analyzed by FACS. Data are representative of 3 experiments $(\mathbf{A}-\mathbf{F})$. Error bars indicate mean \pm SD. Data were analyzed using the Student's $t$ test; ${ }^{* *} P<0.001$.

Antigen sampling of the luminal content of the gut is a prerequisite for monitoring both harmless and harmful antigens, and for responding appropriately. In the small intestine, efficient encounter between APCs and antigen-specific T cells takes place in specialized secondary lymphoid organs, that is, mLNs and PPs. Particularly, M cells and the follicle-associated epithelium (FAE) of PPs have been shown to efficiently take up and transport antigens from the gut lumen to immune-inductive sites of PPs $(30,31)$.

Our search for diet-activated $\mathrm{T}$ cells in gut-associated and systemic lymphoid tissues revealed an unusually high frequency of activated $\mathrm{CD}_{4} 4^{+} \mathrm{Helios}^{+} \mathrm{Foxp}^{-} \mathrm{CD} 4^{+} \mathrm{T}$ cells exclusively in PPs of SPF and GF mice, indicating that activation was mediated by dietary rather than microbial antigens. This finding is in accordance with a previous observation that antigen-experienced $\mathrm{T}$ cells naturally accumulate in PPs but not mLNs with age, suggesting that these cells received antigenic stimulation directly in PPs and not in other sites of the intestine. Only a small proportion of these PP-resident CD62L- ${ }^{-} \mathrm{CD} 4^{+}$cells were follicular helper $\mathrm{T}$ cells (Tfh) or Tregs (32). In contrast, Tregs became a prominent population in the siLP after weaning of GF animals to ConvD, and alimentation with ED prevented the development of Tregs in the siLP (10).

Preferential expansion of pTregs in the siLP and Helios ${ }^{+}$ Foxp3 ${ }^{-C D} 4^{+} \mathrm{T}$ cells in PPs seems to reflect the distinct morphology of both tissue sites. In PPs, the majority of DCs express CCR6 and recruit antigen from the subepithelial dome (SED) region before clustering with antigen-specific $\mathrm{CD} 4^{+} \mathrm{T}$ cells in the PPs but not in LP, supporting their selective role in intestinal-inductive sites (33). In contrast, the majority of LP DCs express $\mathrm{CX}_{3} \mathrm{CR} 1$, are $\mathrm{CD}_{103}{ }^{+}$, and capture antigen from the intestinal lumen via transepithelial dendrites (34). In the presence of TGF- $\beta$ and retinoic acid, LP-derived
$\mathrm{CD} 13^{+} \mathrm{CD} 11 \mathrm{~b}^{+}$DCs have been shown to efficiently induce Foxp3 ${ }^{+}$ Tregs $(35,36)$. Surprisingly, their role in mediating oral tolerance still remains enigmatic, as oral tolerance was intact in CD11b- DC-deficient animals with strongly reduced pTregs (11).

We here describe a population of ConvD-activated CD $44^{+}$ Helios ${ }^{+}$Foxp $3^{-} \mathrm{CD}^{+}{ }^{+} \mathrm{T}$ cells in PPs that is distinct from pTregs, although they express Helios, a marker recently used for differentiation between natural and inducible Foxp $3^{+}$Tregs (37). Since transient expression of Foxp3 has been described (38), there is a possibility that food-reactive $\mathrm{CD} 44^{+} \mathrm{Helios}^{+} \mathrm{Foxp} 3^{-} \mathrm{CD} 4^{+} \mathrm{PP} \mathrm{T}$ cells may have originated from an "exFoxp3" population. Such reprogramming is highly unlikely as the frequency of Foxp $3^{+}$Tregs in PPs was not affected by the type of diet, whereas the Helios ${ }^{+}$ Foxp3 $3^{-}$population expanded or shrank in the presence or absence of dietary antigens, respectively.

The mechanism of Foxp3-independent Helios expression and its function in activated PP CD4 ${ }^{+} \mathrm{T}$ cells remains unresolved. Autonomous expression of Helios has been described during differentiation and activation of $\mathrm{CD}^{+} \mathrm{T}$ cells, for Tfh cells and autoreactive $\mathrm{T}$ cells undergoing apoptosis $(27,39)$. It is notable that oral antigen uptake preferentially induces IL-27 and IL-10 in PP DCs, both cytokines exhibiting antiinflammatory properties $(40,41)$. Correspondingly, we observed that lack of dietary protein vastly decreased the number of Helios ${ }^{+} \mathrm{CD} 4^{+} \mathrm{T}$ cells and the amount of IL-10 in PPs.

Although we were unable to directly track food-reactive T cells in normal mice, analysis of OT-II animals revealed TCR-specific recognition of dietary antigens. Oral uptake of OVA induced the Helios ${ }^{+}$Foxp3- $3^{-}$phenotype within the TCR-transgenic ${\mathrm{V} \alpha 2^{+}}^{+}$population, whereas normal chow induced Helios in the endogenous $\mathrm{V} \alpha 2^{-} \mathrm{CD} 4^{+} \mathrm{T}$ cell population within PPs. 
A

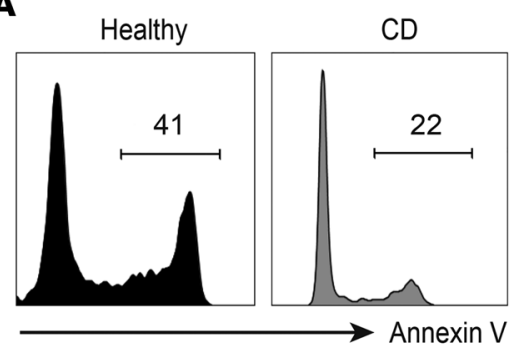

C

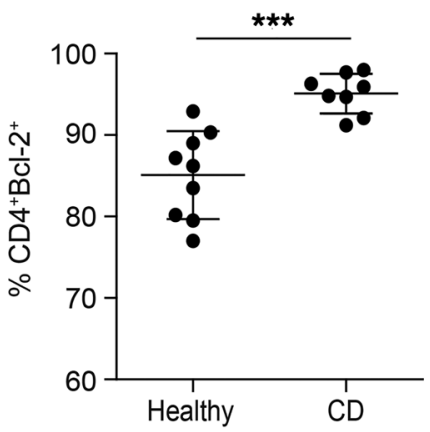

B

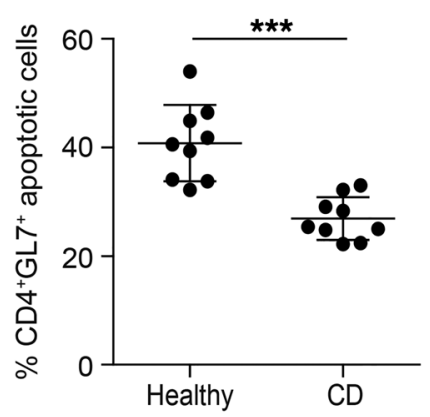

D

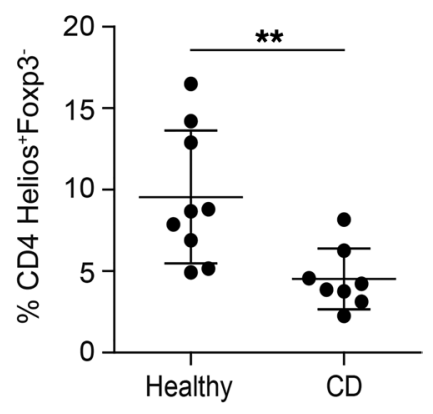

Figure 8. Analysis of CD4+ $\mathrm{T}$ cells from human Peyer patches. (A) Representative histogram of annexin $\mathrm{V}$ staining for $\mathrm{GL7} 7^{+} \mathrm{CD} 4^{+} \mathrm{T}$ cells derived from PPs of patients with Crohn's disease (CD) and healthy controls. (B) Frequencies of annexin $\mathrm{V}^{+} / \mathrm{Pl}^{+} \mathrm{CL} 7^{+} \mathrm{CD} 4^{+} \mathrm{T}$ cells in PPs. (C) Expression of Bcl2 on PP CD4+ $T$ cells. (D) Percentages of Helios ${ }^{+}$Foxp3-PP CD4 ${ }^{+} T$ cells. Results are expressed as mean \pm SEM; $n=9$ per healthy group and $n=8-9$ per CD group. Data were analyzed using Mann-Whitney $U$ test; ${ }^{* *} P<0.01,{ }^{* *} P<0.001$.

antigens (3). In this context, clinical observations have suggested lymphoid follicles as the initial site of inflammation in patients with $C D$, and that peak frequency of $\mathrm{CD}$ correlates with peak number of PPs at an age between 15 and 25 years (46-48).

Here, we present an approach that combines murine and human studies for characterization of intestinal immune responses against dietary antigens. Our data suggest that apoptosis of PP lymphocytes is a hallmark of the healthy intestine, which eliminates potentially harmful food-reactive $\mathrm{T}$ cells and triggers the production of local IL-10. Reduced

An important consequence of food antigen recognition by the intestinal immune system is the cellular and functional maturation of the small intestine. In the absence of food antigens, a low amount of IgA together with reduced numbers of B and T cells, including Tfh cells, assigns a new and essential aspect to dietary proteins aside from nutrition; that is, their antigenicity is required for normal development and function of the small intestine.

Because the accumulation of diet-specific T cells in PPs might cause severe immunopathology if their activity and lifespan remain uncontrolled, we investigated the fate of these cells. In accordance with the downregulation of survival molecules, an exceptionally high level of apoptotic cells was found within the PPs. This increase was confined to the activated $\mathrm{CD} 44^{+} \mathrm{Helios}^{+} \mathrm{Foxp}^{-} \mathrm{CD} 4^{+} \mathrm{T}$ cell population and was decreased in ED animals, suggesting that caspase-3-mediated apoptosis of diet-activated $\mathrm{T}$ cells is a default mechanism, which warrants intestinal homeostasis.

Helios ${ }^{+}$Foxp $^{-} \mathrm{CD}^{+}{ }^{+}$PP T cells expressed high levels of PD-1, a molecule known to fine tune the fate and the function of $\mathrm{T}$ cells (42). We observed that anti-PD-1 treatment of PP T cells triggered IFN- $\gamma$ production and simultaneously reduced the frequencies of apoptotic $\mathrm{CD}^{+} \mathrm{T}$ cells, indicating that PD- 1 blockade rescues dysfunctional $\mathrm{T}$ cells from cell death. Interestingly, in the absence of IL-10, blocking of PD-1 favored development of colitis in these mice. Numerous reports show that colitis development remains a complication after treatment of cancer patients with an anti-PD-1 checkpoint inhibitor (43-45).

In line with our murine data, we found that PP CD $4^{+} \mathrm{T}$ cells from healthy donors but not patients with $\mathrm{CD}$ revealed a substantially increased frequency of apoptotic $\mathrm{T}$ cells with high expression of Helios and low expression of Bcl2. Although we have not yet identified the precise mechanisms for enhanced survival of PP CD $4^{+} \mathrm{T}$ cells in patients with IBD, disturbed apoptosis might explain food antigen-specific immune responses in patients with $\mathrm{CD}$, which were ameliorated by restricting dietary apoptosis of PP T cells in patients with $\mathrm{CD}$ might explain the beneficial effects of ED by depriving these T cells of their antigenic stimulus. These questions underline the importance of further investigating the molecular and cellular mechanisms of increased survival of PP T cells in patients with CD.

\section{Methods}

Animals. C57BL/6 mice were purchased from Charles River Laboratories and kept under specific pathogen-free (SPF) conditions. DEREG mice were provided by Tim Sparwasser (Institute of Infection Immunology, Hannover, Germany). IL10 ${ }^{-/-}$mice, OT-II, and GF C57BL/6 mice were bred at the animal facilities at the University of Marburg. GF mice generated via rederivation through cesarean section were a gift of Petra Kirsch (University of Ulm). GF animals were kept in plastic isolators (Metall and Plastik) with autoclaved food, bedding, and water. Sterility of animals was checked biweekly by culturing feces in thioglycollate medium under aerobic and anaerobic conditions for at least 10 days. All handling procedures for GF mice were conducted in a laminar flow hood under sterile conditions.

Antibiotic sterilization of mice. To deplete the commensal gut microbiota, 6- to 8-week-old ConvD mice were transferred to sterile cages and orally treated with antibiotic cocktail $(1 \mathrm{~g} / \mathrm{l}$ ampicillin, $0.5 \mathrm{~g} / \mathrm{l}$ vancomycin, $1 \mathrm{~g} / \mathrm{l}$ metronidazole, $0.25 \mathrm{~g} / \mathrm{l}$ imipenem, and $0.2 \mathrm{~g} / \mathrm{l}$ ciprofloxacin) for 8 weeks according to a standard protocol (49). Bottles with antibiotic-containing drinking water were replaced once per week. The intestinal microbial status was tested weekly by culturing fecal samples under aerobic and anaerobic conditions in thioglycollate broth.

Animal nutrition. C57BL/6 mice (SPF and GF) at 6-20 weeks of age were used. The ConvD group were kept on a conventional chow (LASQCdietRod16, LASvendi) and food antigen-free, ED mice were kept on an amino acid-containing diet for up to 5 generations. Pellets of ED diet (ssniff, S7242-E014/-E714) contained all essential vitamins, minerals, trace elements, fat, dextrin, sucrose, and free amino acids 
equimolar to the protein content of normal rodent chow. In summary, the ED pellets contained $20 \%$ corn starch, $44 \%$ sucrose, $7 \%$ cellulose, $17.5 \%$ amino acid mixture, $1 \%$ vitamin premix w/o choline, $5 \%$ mineral trace element premix, $0.2 \%$ choline $\mathrm{Cl}, 02 \%$ sodium bicarbonate, $0.02 \%$ butylated hydroxytoluene, $5 \%$ corn oil.

Oral administration of OVA. The drinking water was supplemented with $1 \mathrm{mg} / \mathrm{ml}$ OVA (Sigma-Aldrich) for low-dose OVA application. OVA-supplemented water was given to OT-II animals for 5 or 7 days prior to analysis.

Isolation of lamina propria mononuclear cells. Single-cell suspensions were performed from spleen, mLNs, and PPs by mechanical disruption and passage through filter (Milteny Biotec). Lamina propria mononuclear cells (LPMCs) of the colon and small intestine were isolated after enzymatic digestion of intestinal tissue pieces with collagenase D and collagenase VIII (MilliporeSigma, 0.4 $\mathrm{mg} / \mathrm{ml}$ each). Cells were purified by Percoll gradient (40\%/70 \%). LPMCs were collected from the interphase, washed, and resuspended in complete medium.

Small intestinal IgA. The complete small intestine was flushed with $5 \mathrm{ml} \mathrm{PBS} / 2 \%$ milk powder, and the intestinal liquid was collected, homogenized, and centrifuged (850g, 30 minutes). Supernatants were used for IgA ELISA. In brief, flat-bottom 96-well plates (NUNC) were coated with rabbit-anti-mouse IgA (Rockland) overnight. After blocking with PBS $/ 10 \%$ FCS, $50 \mu$ intestinal liquid was incubated for 3 hours at $4^{\circ} \mathrm{C}$, washed twice, and IgA was detected by adding the secondary rabbit-anti-mouse IgA HRP and TMB (R\&D Systems). The enzymatic reaction was stopped by the addition of sulphuric acid and absorption was measured with an ELISA Reader (FLUOstar Omega, BMG Labtech).

IL-1O ELISA. Single-cell suspensions from PPs, mLNs, and spleen of Conv and ED mice were cultured at a density of $2 \times 10^{6}$ cells $/ 200$ $\mu$ RPMI medium in round-bottom 96-well tissue-culture plates for 24 hours. The next day, cell-culture supernatants were collected and IL-10 secretion was measured using a murine IL-10 ELISA kit (BD Bioscience) according to the manufacturer's instructions.

Antibodies, reagents, and staining methods. The following antibodies were obtained from eBioscience unless otherwise stated: antiCD4 (RM4-5, BioLegend), anti-CD127 (A7R34), anti-CD62L (MEL14), anti-CD44 (IM7, BD Biosciences), anti-CD25 (PC61.5), anti-V 22 (B20.1), anti-B220 (RA3-6B2, BD Biosciences), anti-CD69 (H1.2F3), anti-CTLA-4 (UC10-4F10-11, BD Biosciences), anti-OX40 (OX-86), anti-CXCR5 (2G8, BD Biosciences), TCR V $\beta$ screening panel (BD Biosciences), anti-Bcl2 (10C4), anti-PD-L1 (MIH7, BioLegend), and antiPD-L2 (catalog 122). Anti-CD279 (anti-PD-1, clone J43) for in vivo application was purchased from Höltzel diagnostika. Detection of apoptotic cells was performed with annexin-V-FLUOS staining kit (Roche Applied Science). For intracellular cytokine staining, PP cells were stimulated for 4 hours with PMA (50 ng/ml) and ionomycin $(750 \mathrm{ng} / \mathrm{ml})$ in the presence of Brefeldin A (5 $\mu \mathrm{g} / \mathrm{ml}$, MilliporeSigma). Subsequently, cells were stained with anti-CD4, fixed, and permeabilized in $0.3 \%$ saponine buffer before staining for cytokines. Intracellular staining was performed for anti-IL-10 (JES5-16E3). Foxp3- and Helios-expressing cells were routinely detected by Foxp3 staining kit (eBioscience), antiFoxp3 (FJK-16s), and anti-Helios (22F6). Cells were analyzed by flow cytometry using the FlowJo software (Tree Star).

RNA-Seq and bioinformatical analysis. RNA was purified from sorted PP CD4 ${ }^{+} \mathrm{T}$ cells of ConvD and ED mice with the RNeasy Plus Micro Kit according to the manufacturer's protocol (Qiagen). RNA was quantified with a Qubit 2.0 fluorometer (Invitrogen) and the quality was assessed on a Bioanalyzer 2100 using an RNA 6000 Pico chip (both from Agilent). Samples with an RNA integrity number (RIN) of greater than 8 were used for library preparation. Barcoded mRNA-Seq cDNA libraries were prepared from 10 ng total RNA using NEBNext Poly(A) mRNA Magnetic Isolation Module and NEBNext Ultra II RNA Library Prep Kit for Illumina (New England Biolabs) according to the manual. Quantity was assessed using Invitrogen's Qubit HS assay kit and library size was determined using Agilent's 2100 Bioanalyzer HS DNA assay. Barcoded RNA-Seq libraries were onboard clustered using HiSeq Rapid SR Cluster Kit v2 using 8 pM, and 59 bps were sequenced on the Illumina HiSeq2500 using HiSeq Rapid SBS Kit v2 (59 cycle). The raw output data of the HiSeq were preprocessed according to the Illumina standard protocol. After initial quality assessment with the FastQC software (available online at http://www.bioinformatics. babraham.ac.uk/projects/fastqc/), raw output fastq sample files were trimmed and mapped with the Qiagen CLC Workbench v.10.0.1, using the murine genome version GRCm38. Total read counts were further processed in $\mathrm{R}$, using the DeSeq2 package to compute differential gene expression and adjusted $P$ values. Normalized read counts were ranked and investigated for pathway-specific enrichment by GSEA (available online at http://software.broadinstitute.org/gsea/index.jsp) and were used for graphic representation of differential expression. The RNA-Seq microarray data were deposited in the NCBI's Gene Expression Omnibus database (GEO GSE124286) and are available at https://www.ncbi.nlm.nih.gov/geo/query/acc.cgi?acc=GSE124286.

Anti-PD-1 treatment of mice and cell cultures. WT and IL-10-deficient mice (C57BL/6 background) were administered $100 \mu \mathrm{g}$ antiPD-1 Ab (clone J43, Hölzel diagnostika) i.p. on days 0, 4, 8, and 12. As isotype control, animals were injected with $100 \mu \mathrm{g}$ polyclonal Armenian hamster IgG (Hölzel diagnostika). On day 15, mice were analyzed for signs of inflammation and intestinal $\mathrm{CD} 4^{+} \mathrm{T}$ cells were collected and analyzed for apoptosis and cytokine expression by flow cytometry.

For in vitro studies, $3 \mu \mathrm{g} / \mathrm{ml}$ anti-PD-1 mAb together with $2.5 \mu \mathrm{g} /$ $\mathrm{ml}$ anti-CD3/CD28 were added to single-cell suspensions from PPs. After 3 days of culture, cells were stimulated for 4 hours with PMA/ ionomycin in the presence of Brefeldin A and analyzed by FACS.

Human Peyer patch T cells. Cells from PP biopsies were isolated by mechanical dissociation through $100-\mu \mathrm{m}$ and $40-\mu \mathrm{m}$ cell strainers. The strainers were washed with RPMI 1640 plus 1\% Pen/Strep plus $10 \%$ FCS (Life Technologies, Gibco) and cells were centrifuged at $400 \mathrm{~g}$ for 10 minutes at $4^{\circ} \mathrm{C}$ and resuspended in PBS (Life Technologies, Gibco) for flow cytometric analyses. For surface staining, fluorochrome-conjugated antibodies CD4 (RPA-T4) and GL7 were added and incubated for 15 minutes at $4^{\circ} \mathrm{C}$. For the annexin $\mathrm{V}$ staining, cells were resuspended in binding buffer and stained with annexin $\mathrm{V}$ and 7-AAD (Annexin V Apoptosis Detection Kit, eBioscience). For intracellular staining of cytokines and transcription factors (Bcl2 [100/ D5+124], Foxp3 [PCH101], and Helios [22F6]), cells were fixed, permeabilized, and stained using the Foxp3 staining kit (eBioscience). Flow cytometry analysis was performed on a FACS Canto II (BD Bioscience). Data were analyzed with FlowJo analysis software.

Treg suppression assay. Suppressive properties of Tregs and $\mathrm{CD}^{+}{ }^{+}$Helios ${ }^{+}$Foxp3 $^{-}$cells from PPs were compared. CD $4^{+} \mathrm{GFP}^{-}$ responder $\mathrm{T}$ cells from spleen and enriched Helios-expressing CD4 ${ }^{+}$ $\mathrm{GFP}^{-} \mathrm{CD} 44^{+} \mathrm{CD} 62 \mathrm{~L}^{-} \mathrm{T}$ cells were sorted from PPs of DEREG mice. As positive control, iTregs were generated from sorted naive $\mathrm{CD} 4^{+} \mathrm{T}$ cells 
of DEREG mice. In brief, cells were activated by plate-bound anti-CD3 $(5 \mu \mathrm{g} / \mathrm{ml} ; 145-2 \mathrm{C} 11)$ and soluble anti-CD28 $(1 \mu \mathrm{g} / \mathrm{ml} ; 37.51)$ in the presence of IL-2 (50 U/ml, Novartis), TGF- $\beta 1$ ( $2 \mathrm{ng} / \mathrm{ml}, \mathrm{R} \& D$ Systems), anti-IL-4 (10\% culture supernatant of clone 11B11), and anti-IFN- $\gamma(5$ $\mu \mathrm{g} / \mathrm{ml}, \mathrm{XMG1}-2)$ for 3 days. Responder T cells were labeled with CFSE and cocultured for 3 days with Tregs or Helios-expressing $\mathrm{T}$ cells from PPs in the presence of $1 \mu \mathrm{g} / \mathrm{ml}$ soluble anti-CD3 (clone 145-2C11) and irradiated $\mathrm{T}$ cell-depleted splenocytes. Proliferative responses of responder cells were analyzed by FACS.

BrdU incorporation assay. To label proliferating cells in vivo, $1 \mathrm{mg}$ BrdU (Sigma-Aldrich) in $200 \mu \mathrm{l}$ PB was injected i.p. and animals were subsequently supplied with $\mathrm{BrdU}(0.8 \mathrm{mg} / \mathrm{ml})$ in drinking water for 5 days. Cell suspensions were stained with anti-CD4 and anti-BrdU (eBioscience). The percentage of BrdU ${ }^{+} \mathrm{T}$ cells was assessed by FACS.

Western blot analysis. CD $44^{+}$and $\mathrm{CD} 44^{-} \mathrm{T}$ lymphocytes were sorted from PPs of C57BL/ 6 mice and lysed directly in $4 \times$ Laemmli sample buffer (with $5 \%$ B-mercaptoethanol). Proteins were separated by SDS-PAGE and transferred to nitrocellulose membrane. The following antibodies were used for immunoblot analysis: anti-GAPDH as loading control, mouse anti-PARP, rabbit anti-caspase-3, mouse anticaspase-8, and rabbit anti-caspase-9 (Cell Signaling Technology).

Immunofluorescence analysis. Tissue samples were snap frozen in methylbutane cooled with liquid nitrogen. Cryosections of about $5 \mu \mathrm{m}$ were made with a Frigocut $2800 \mathrm{E}$ (Leica), air-dried, and incubated for 20 minutes in ice-cold acetone and stored at $-20^{\circ} \mathrm{C}$ or washed 3 times with PBST for immunostaining. Following incubation in antibody diluent (Dako), samples were incubated with primary antibodies for 2 hours at room temperature followed by washing 3 times in PBST. The following primary antibodies were used: anti-mouse CD4-Alexa Fluor 646 (BioLegend) and anti-mouse GL7-FITC (BD Biosciences). Confocal images of cryosections were acquired by fluorescence microscopy on a Leica TCS SP2 microscope (Leica Microsystems).

Statistics. Statistical analysis was performed using Prism software (GraphPad Software). Results are generally expressed as the mean \pm
SEM. Data were analyzed using the Student's $t$ test or Mann-Whitney $U$ test as indicated. Values with $P$ less than or equal to 0.05 were considered statistically significant.

Study approval. All patients gave written consent after approval by the Charité ethics committee (EA4/097/14). All animal experiments were conducted in accordance with German animal protection laws and were approved by the RP-Giessen (MR 20/61/2018 and EX7-2015).

\section{Author contributions}

US and AV directed and designed the experiments and analyzed the data. PWB, OP, ML, and BS gave scientific advice and critically read the manuscript. AV, SH, ML, HR, RR, and FF performed the animal experiments and in vitro studies. RJ and AP performed the histological analysis. HM, WB, and MK performed and evaluated RNA-Seq experiments. KR performed the molecular and biochemical studies. YRS, RG, and BS conducted the human studies. US and AV wrote the manuscript.

\section{Acknowledgments}

We thank Anne Hellhund and Carrie Anderson for expert technical help and Guido Schemken, Hosam Shams-Eldin, and Claudia Trier for the animal care. We thank Allan Mowat and Ayse Kilic for discussion and critical reading of the manuscript. Parts of this work were funded by BMBF (Federal Ministry of Education and Research, JPI-AMR - FKZ 01K11702; ERACoSysMed2 - SydMed-COPD - FKZ 031L0140) and DFG (German Research Foundation, SFB/TR-84 TP C01) to BS. This study was supported by the von Behring-Röntgen-Stiftung (66-0008) and the DFG Priority Programm to US (STE 776/3-1) and BS (SI 749/9-1).

Address correspondence to: Ulrich Steinhoff, Institute for Medical Microbiology and Hospital Hygiene, Phillips University, Hans-Meerweinstr. 2, 35043 Marburg, Germany. Phone: 49.6421.286.6134. Email: ulrich.steinhoff@staff.uni-marburg.de.
1. Brandtzaeg P. Food allergy: separating the science from the mythology. Nat Rev Gastroenterol Hepatol. 2010;7(7):380-400.

2. Pabst O, Mowat AM. Oral tolerance to food protein. Mucosal Immunol. 2012;5(3):232-239.

3. Kawaguchi T, et al. Food antigen-induced immune responses in Crohn's disease patients and experimental colitis mice. J Gastroenterol. 2015;50(4):394-405.

4. Nakahigashi M, Yamamoto T, Sacco R, Hanai H, Kobayashi F. Enteral nutrition for maintaining remission in patients with quiescent Crohn's disease: current status and future perspectives. Int $J$ Colorectal Dis. 2016;31(1):1-7.

5. Assor E, Marcon MA, Hamilton N, Fry M, Cooper T, Mahmud FH. Design of a dietary intervention to assess the impact of a gluten-free diet in a population with type 1 Diabetes and Celiac Disease. BMC Gastroenterol. 2015;15:181.

6. Groetch M, Nowak-Wegrzyn A. Practical approach to nutrition and dietary intervention in pediatric food allergy. Pediatr Allergy Immunol. 2013;24(3):212-221

7. Chen Y, Kuchroo VK, Inobe J, Hafler DA, Weiner HL. Regulatory T cell clones induced by oral tolerance: suppression of autoimmune encepha- lomyelitis. Science. 1994;265(5176):1237-1240.

8. Chen Y, Inobe J, Marks R, Gonnella P, Kuchroo VK, Weiner HL. Peripheral deletion of antigen-reactive T cells in oral tolerance. Nature. 1995;376(6536):177-180.

9. Friedman A, Weiner HL. Induction of anergy or active suppression following oral tolerance is determined by antigen dosage. Proc Natl Acad Sci US A. 1994;91(14):6688-6692.

10. Kim KS, et al. Dietary antigens limit mucosal immunity by inducing regulatory $\mathrm{T}$ cells in the small intestine. Science. 2016;351(6275):858-863.

11. Esterházy D, Loschko J, London M, Jove V, Oliveira TY, Mucida D. Classical dendritic cells are required for dietary antigen-mediated induction of peripheral $\mathrm{T}$ (reg) cells and tolerance. Nat Immunol. 2016;17(5):545-555.

12. Fujihashi K, et al. Peyer's patches are required for oral tolerance to proteins. Proc Natl Acad Sci U S A 2001;98(6):3310-3315.

13. Kraus TA, et al. Induction of mucosal tolerance in Peyer's patch-deficient, ligated small bowel loops. J Clin Invest. 2005;115(8):2234-2243.

14. Mucida D, Kutchukhidze N, Erazo A, Russo M, Lafaille JJ, Curotto de Lafaille MA. Oral tolerance in the absence of naturally occurring Tregs. J Clin
Invest. 2005;115(7):1923-1933.

15. Song F, et al. The Peyer's patch is a critical immunoregulatory site for mucosal tolerance in experimental autoimmune encephalomylelitis (EAE). J Autoimmun. 2008;30(4):230-237.

16. Chung H, et al. Gut immune maturation depends on colonization with a host-specific microbiota. Cell. 2012;149(7):1578-1593.

17. Akimova T, Beier UH, Wang L, Levine MH, Hancock WW. Helios expression is a marker of $\mathrm{T}$ cell activation and proliferation. PLoS One. 2011;6(8):e24226.

18. Bilate AM, Lafaille JJ. Induced CD4+Foxp3+ regulatory T cells in immune tolerance. Annu Rev Immunol. 2012;30:733-758.

19. Gottschalk RA, Corse E, Allison JP. Expression of Helios in peripherally induced Foxp $3+$ regulatory T cells. J Immunol. 2012;188(3):976-980.

20. Scurr M, et al. Highly prevalent colorectal cancer-infiltrating $\mathrm{LAP}^{+} \mathrm{Foxp}^{+} \mathrm{T}$ cells exhibit more potent immunosuppressive activity than Foxp $3^{+}$regulatory T cells. Mucosal Immunol. 2014;7(2):428-439.

21. Rogers PR, Song J, Gramaglia I, Killeen N, Croft M. OX40 promotes Bcl-xL and Bcl-2 expression and is essential for long-term survival of CD4 
T cells. Immunity. 2001;15(3):445-455.

22. Chung EY, et al. Interleukin-10 expression in macrophages during phagocytosis of apoptotic cells is mediated by homeodomain proteins $\mathrm{Pbx} 1$ and Prep-1. Immunity. 2007;27(6):952-964.

23. Voll RE, Herrmann M, Roth EA, Stach C, Kalden JR, Girkontaite I. Immunosuppressive effects of apoptotic cells. Nature. 1997;390(6658):350-351.

24. Sharpe AH, Pauken KE. The diverse functions of the PD1 inhibitory pathway. Nat Rev Immunol. 2018;18(3):153-167.

25. Scheinin T, Butler DM, Salway F, Scallon B, Feldmann M. Validation of the interleukin-10 knockout mouse model of colitis: antitumour necrosis factor-antibodies suppress the progression of colitis. Clin Exp Immunol. 2003;133(1):38-43.

26. Rebollo A, Schmitt C. Ikaros, Aiolos and Helios: transcription regulators and lymphoid malignancies. Immunol Cell Biol. 2003;81(3):171-175.

27. Daley SR, Hu DY, Goodnow CC. Helios marks strongly autoreactive $\mathrm{CD} 4+\mathrm{T}$ cells in two major waves of thymic deletion distinguished by induction of PD-1 or NF-кB. J Exp Med. 2013;210(2):269-285.

28. O'Moráin C, Segal AW, Levi AJ. Elemental diet as primary treatment of acute Crohn's disease: a controlled trial. $\mathrm{Br} \mathrm{Med}$ J(Clin Res Ed). 1984;288(6434):1859-1862.

29. Hunter J. Elemental diet and the nutritional treatment of Crohn's disease. Gastroenterol Hepatol Bed Bench. 2015;8(1):4-5.

30. Kunkel D, Kirchhoff D, Nishikawa S, Radbruch A, Scheffold A. Visualization of peptide presentation following oral application of antigen in normal and Peyer's patches-deficient mice. Eur J Immunol. 2003;33(5):1292-1301.

31. Nagata S, et al. Human Peyer's patch T cells are sensitized to dietary antigen and display a Th cell type 1 cytokine profile. J Immunol. 2000;165(9):5315-5321.

32. Ugur M, Schulz O, Menon MB, Krueger A, Pabst $\mathrm{O}$. Resident CD4+ T cells accumulate in lymphoid organs after prolonged antigen exposure. Nat Commun. 2014;5:4821.

33. Salazar-Gonzalez RM, et al. CCR6-mediated dendritic cell activation of pathogenspecific $\mathrm{T}$ cells in Peyer's patches. Immunity. 2006;24(5):623-632.

34. Niess JH, et al. CX3CR1-mediated dendritic cell access to the intestinal lumen and bacterial clearance. Science. 2005;307(5707):254-258.

35. Coombes JL, et al. A functionally specialized population of mucosal CD103+ DCs induces Foxp3+ regulatory $\mathrm{T}$ cells via a TGF-beta and retinoic acid-dependent mechanism. J Exp Med. 2007;204(8):1757-1764.

36. Sun CM, et al. Small intestine lamina propria dendritic cells promote de novo generation of Foxp3 T reg cells via retinoic acid. JExp Med. 2007;204(8):1775-1785.

37. Thornton AM, et al. Expression of Helios, an Ikaros transcription factor family member, differentiates thymic-derived from peripherally induced Foxp3+ T regulatory cells. J Immunol. 2010;184(7):3433-3441.

38. Miyao T, et al. Plasticity of Foxp3(+) T cells reflects promiscuous Foxp3 expression in conventional $\mathrm{T}$ cells but not reprogramming of regulatory T cells. Immunity. 2012;36(2):262-275.

39. Serre $\mathrm{K}$, et al. Helios is associated with CD4 T cells differentiating to $\mathrm{T}$ helper 2 and follicular helper $\mathrm{T}$ cells in vivo independently of Foxp3 expression. PLoS One. 2011;6(6):e20731.

40. Diveu C, et al. IL-27 blocks RORc expression to inhibit lineage commitment of Th17 cells. JImmunol. 2009;182(9):5748-5756.

41. Fitzgerald DC, et al. Suppression of autoimmune inflammation of the central nervous system by interleukin 10 secreted by interleukin 27-stimulated T cells. Nat Immunol. 2007;8(12):1372-1379.

42. Keir ME, Butte MJ, Freeman GJ, Sharpe AH. PD-1 and its ligands in tolerance and immunity. Annu Rev Immunol. 2008;26:677-704.

43. Bertha M, Bellaguara E, Kuzel T, Hanauer S. Checkpoint inhibitor-induced colitis: a new type of inflammatory bowel disease? ACG Case Rep J. 2017;4:e112.

44. Chen JH, Pezhouh MK, Lauwers GY, Masia R. Histopathologic features of colitis due to immunotherapy with anti-PD-1 antibodies. Am J Surg Pathol. 2017;41(5):643-654.

45. Kim J, et al. Anti-PD-1 induced colitis: a case series of 25 patients. Gastroenterology. 2017;152(5):S811.

46. Fujimura Y, Kamoi R, Iida M. Pathogenesis of aphthoid ulcers in Crohn's disease: correlative findings by magnifying colonoscopy, electron microscopy, and immunohistochemistry. Gut. 1996;38(5):724-732.

47. Fujimura Y, Hosobe M, Kihara T. Ultrastructural study of M cells from colonic lymphoid nodules obtained by colonoscopic biopsy. Dig Dis Sci. 1992;37(7):1089-1098.

48. Van Kruiningen HJ, Ganley LM, Freda BJ. The role of Peyer's patches in the age-related incidence of Crohn's disease. J Clin Gastroenterol. 1997;25(2):470-475.

49. Rakoff-Nahoum S, Paglino J, Eslami-Varzaneh F, Edberg S, Medzhitov R. Recognition of commensal microflora by toll-like receptors is required for intestinal homeostasis. Cell. 2004;118(2):229-241. 